\title{
EFFECT OF OXYGEN ON DEVELOPING RETINAL VESSELS WITH PARTICULAR REFERENCE TO THE PROBLEM OF RETROLENTAL FIBROPLASIA
}

\author{
BY
}

\author{
NORMAN ASHTON, BASIL WARD, and GEOFFREY SERPELL
}

Department of Pathology, Institute of Ophthalmology, University of London.

THE evidence for regarding an abnormal overgrowth of the developing retinal vessels as the pathological basis of retrolental fibroplasia has been reviewed and discussed in an earlier paper in this issue (Ashton, 1954a). This fundamental dysplasia considered alone appeared to indicate that the disease was probably no more than a violent activation of the normal process of retinal vascularization, so that the narrow confines of the nerve fibre layer could no longer contain the exuberant vaso-formative tissue, which consequently burst through the limiting membrane to invade the vitreous and so initiated a train of events terminating in total retinal detachment and the formation of a retrolental fibrous membrane. The stimulus which normally attracts the vessels into the retina is itself unknown, but it has been assumed, in general terms, to be a response to the oxygen demands of the inner layers of the retina, which the choroidal circulation is no longer able to satisfy as the eye develops. If retrolental fibroplasia began simply as an overgrowth of normal vaso-formative tissue, it seemed possible that it might occur in response to a stimulus identical in nature with the normal but excessive in degree, a variation which thus appeared to be related to a disparity between oxygen supply and demand.

On such a basis, however, it was difficult if not impossible to reconcile the apparently conflicting theories that retrolental fibroplasia was due to anoxia (Ingalls, 1948; Szewczyk, 1951, 1952; Ingalls and others, 1952; Rubinstein, 1952), or to the toxic effects of high oxygen (K. Campbell, 1951; Ryan, 1952; Goldman and Tobler, 1952; Patz and others, 1952; Von Winning, 1952), or to a relative anoxia following high oxygen administration (Crosse and Evans, 1952; Jefferson, 1952), or that oxygen was not causative or might be only one of the factors concerned (Houlton, 1951; Bembridge and others, 1952; Zacharias, 1952; Silverman and others, 1952). In an attempt to clarify the aetiological problem, it was therefore decided to carry out an experimental investigation of the influence of varying concentrations of oxygen upon the developing retinal vasculature in the kitten, which, as will be seen, is closely comparable to that in man, and a preliminary report on our findings has already been published (Ashton and others, 1953; Ashton, 1954b).

The normal development of the retinal circulation was thoroughly studied in man, the rat, and the cat by Michaelson (1948a, b), and the mode of development was found to be similar in each case. In the human embryo the 
retinal foetal circulation begins to develop from the disc at the $100-\mathrm{mm}$. stage (16th week approximately), and the ingrowth gradually progresses until it reaches the periphery of the retina at the end of the 8th month; hence, in the later months of pregnancy, which particularly concern us in considering the problems of the premature infant, the vascular network is advancing between the equator and the ora serrata. In the cat embryo vascular budding commences at the disc between the 35th and 45th day of intra-uterine life, but it differs from that in man since it does not reach the periphery until about 3 weeks after birth, so that the degree of retinal vascularization in the full-term kitten at birth and in the ensuing 3 weeks is comparable in extent to that in the premature baby. Since, with minor variations, the retinal vascular development is in all other respects very similar to that in man, the kitten appeared to be the ideal animal for our purpose.

In the first few experiments it was discovered that oxygen in high concentrations was able to exert an obliterative effect on the ingrowing retinal complexes (vaso-obliterative phase) which only partially re-opened when the animal was transferred to air; retinal vascularization then recommenced from the disc region and a disordered and profuse ingrowth of vessels extended into the retina and invaded the vitreous (vaso-proliferative phase). Thus was produced a pathological process almost exactly comparable to the early stages of retrolental fibroplasia.

The purpose of the present paper is to give the experimental details of our investigation as far as space will allow, to describe the final outcome of the oxygen effect, which was unknown at the time of the preliminary communication, to report the conditions which affect the extent of the vasoobliterative and vaso-proliferative phases of the process, and to discuss the possible mechanisms involved. Finally an attempt will be made to assess the significance of the phenomena in the aetiology of retrolental fibroplasia.

\section{Material and Methods}

121 kittens of both sexes and 41 mother or foster-mother cats were used in the preliminary study and in the 32 experiments reported here. The mothers were fed on dried milk paste in the morning, and "Kit-e-Kat" in the evening, and were given water ad lib. At the beginning of the investigation several animals were lost through feline virus pneumonitis, but the infection was later controlled by segregating the cats from each other and by taking aseptic precautions between cleaning and feeding each animal. Seven newborn rabbits and 91 ratlings with their mothers were also used in the investigation.

Gas Chambers.-Standard bacteriological incubators $20^{\prime \prime} \times 20^{\prime \prime} \times 24^{\prime \prime}$ were converted for this purpose. The outside doors were removed and a hole was bored in the lower left corner of the inner glass door and a gas-tight metal outlet inserted. The existing thermostat hole in the top of the incubator was used for a sampling tube, and the existing thermometer hole was fitted with a gas inlet tube, both of which reached down into the lower half of the incubator. The sampling tube hung loosely through the thermometer hole so that samples could be taken from various depths within the incubator; a free escape of gas around the tube ensured that the pressure within the chamber did not arise above normal ambient pressures and this was checked with barometric readings. In the lower third of the incubator an animal sawdust tray, on which the cat and litter were placed, was supported on a shelf 4 " from the floor; beneath this shelf trays containing selfindicating soda lime ("Carbosorb") were placed to absorb $\mathrm{CO}_{2}$ and these were replenished 12-hrly. After the animals had been placed in the incubator and the door edges sealed with 
"Sellotape", the gas (oxygen alone or a mixture of nitrogen and oxygen) was passed through the gas inlet tube and extracted by means of an adjustable water vacuum pump from the lower outlet tube, which assisted in the removal of $\mathrm{CO}_{2}$ that otherwise tended to accumulate in the lower part of the incubator. Temperature and hygrometer readings were taken at hourly intervals; the temperature varied between $22^{\circ}$ and $25^{\circ} \mathrm{C}$. and the relative humidity was maintained at 95 per cent.

The chambers were opened for 15-30 minutes at 12-hrly intervals for feeding, cleaning, exercise, and weighing; the gas percentages were restored to the required level in approximately 15-20 minutes and were thereafter maintained at a sufficient gas flow, which, combined with the vacuum extraction, ensured an adequate circulation of gas within the chamber. The gas flows were controlled by means of an Adams gas regulator and a rotameter graduated for oxygen:

The oxygen concentrations were checked with the BOC analyser at half-hourly intervals in the hypoxia experiments, and hourly in the hyperoxia experiments, day and night, throughout the experiments. $\mathrm{CO}_{2}$ readings were made with a Fry's gas analyser (Fry, 1949), and at the same time the oxygen readings of the $\mathrm{BOC}$ analyser were checked. The $\mathrm{CO}_{2}$ readings varied from $0_{-1}$ per cent., occasionally to 2 per cent., rising to a peak at the end of $12 \mathrm{hrs}$. The oxygen analyser was found to give accurate results within $1-2$ per cent.

Controls.-In the early experiments the control kittens were reared in a control incubator in which the conditions (including the $\mathrm{CO}_{2}$ accumulation) were identical with those in the experiment except for the oxygen concentrations, but since the retinal development was in no way affected as compared with a kitten in ordinary atmospheric conditions, subsequent controls were reared in an open cage.

Weight Gain.-A graph was made of the daily gain in weight of each animal. Kittens in hypoxia lost or failed to gain weight but there were no constant variations which could be related to the conditions of air or hyperoxia. Animals fed by a foster-mother tended to show a smaller gain in weight than those with their own mother, but this did not appear to influence the rate of retinal vascularization.

Injection Technique and Method of Examination.-At the end of each experiment the kittens were anaesthetized with $0.25 \mathrm{ml}$. Nembutal (veterinary) intra-peritoneally. The left eye was removed for histological examination and placed in 10 per cent. Formol saline. The thoracic cavity was then opened and the condition of the organs noted; the descending aorta was ligatured and the pericardium incised; a hypodermic needle, connected with polythene tubing to a $55-\mathrm{ml}$. syringe containing Indian ink, was then inserted into the left ventricle, and, after incising the right auricle, $25 \mathrm{ml}$. ink were gently injected. The right eye was then removed and placed in 10 per cent. Formol saline for $12 \mathrm{hrs}$ and subsequently frozen in $\mathrm{CO}_{2}$ snow and opened transversely by an incision through the ora serrata. The specimen was then examined under a dissecting microscope with direct illumination. In the anterior portion the condition of the iris and tunica vasculosa lentis was recorded. In the posterior portion the degree of retinal vascularization and the condition of the hyaloid artery were studied in situ. The retina was then removed in toto, cut radially, mounted flat, and photographed. The maximum outgrowth of vessels from the disc was measured with dividers and recorded.

Histology.-Celloidin sections of the uninjected eye were cut and stained with haematoxylin and eosin, and periodic acid-Schiff stain.

Preliminary Study.-As a preliminary study the injected retinae of normal kittens were examined at the following ages:

at birth, 6 and $12 \mathrm{hrs}, 2,3,5,6,9,1 \mathrm{l}$, and 17 days, and 5 and 8 weeks.

The appearances and mode of development were found to be as Michaelson (1948a, b) had described. The upper temporal complex always gave the maximum outgrowth readings, but the nasal complex was always nearer to the ora. The variation in the extent of vascularization between animals of the same age from different litters was found to be considerable, as Michaelson had also reported, so that it was not satisfactory to compare the test animal with a normal animal of the same age unless they were from the same litter and of comparable weight. In our later experiments, therefore, the experimental kitten was compared with a litter mate of the same age reared in air with a foster mother.

\section{Experimental Findings}

The records of our experiments are unusually complicated and this is partly due to the fact that unexpected deaths among the animals meant that the actual data provided was not always exactly that which had been sought, so that to give an accurate account of the investigation it would be necessary to include both the experimental plan and result as shown in our preliminary report. Space does not, however, permit inclusion of our full experimental protocol, but the essential details 
are presented in Table I (see pp. 402-403), and Tables II, III, and IV (sec Appendix, pp. 430). The histological findings will be described in the text.

Since the conditions of each experiment were influenced by factors beyond our control, such as the varying age of available kittens and the illness or death of animals during an experiment, it is impossible to divide all the experiments into groups which are exactly similar in every detail. It is, therefore, necessary to adopt standard criteria which may be used to classify the results into approximately comparable groups, and the following standards have been employed for this purpose.

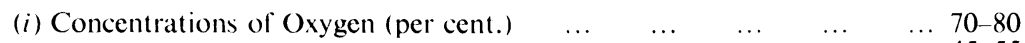

$45-55$

$35-45$

$25-35$

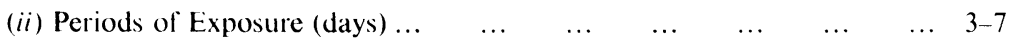

$8-14$

$15-21$

22 and over

(iii) Age Groups according to Age at First Day of Oxygen Exposure (days) 1-7

(iv) Extent of Vaso-Obliterative Effect

$\begin{array}{lll}\text { Total } & \text { Severe } & \text { Moderate } \\ \text { Mild } & \text { Doubtful } & \text { No effect } 0 .\end{array}$

We shall now proceed to analyse the findings, with reference to the appropriate experimental numbers, under the following headings:

(1) Vaso-obliterative effect of hyperoxia.

(2) Factors influencing vaso-obliterative effect:

(a) Degree of maturity of retinal vessels;

(b) Duration of exposure to hyperoxia;

(c) Concentration of oxygen.

(3) Effect of transfer to air after exposure to hyperoxia:

(a) Fate of obliterated vessels;

(h) Vaso-proliferation.

(4) Factors influencing obliterated vessels:

(a) Prolonged hyperoxia;

(b) Hypoxia;

(c) Concentration of carbon dioxide;

(d) Priscol;

(c) Tromexan;

(5) Factors influencing vaso-proliferation;

(a) Duration of exposure to oxygen;

(b) Effect of re-oxygenation.

(6) Effect of hypoxia.

(1) VASO-OBLITERATIVE EFFECT OF HYPEROXIA

High concentrations of oxygen at atmospheric pressure are able to obliterate the ingrowing vessels in the developing retina of the kitten; in some circumstances this effect is complete (Figs 1 and 2) and in others partial. Such results have been obtained repeatedly (complete twelve times in experiments $1,4,7,20,23$, and 24; partial sixteen times in experiments $2,10,11,16,21,25,27,31$, and 36), and it has 


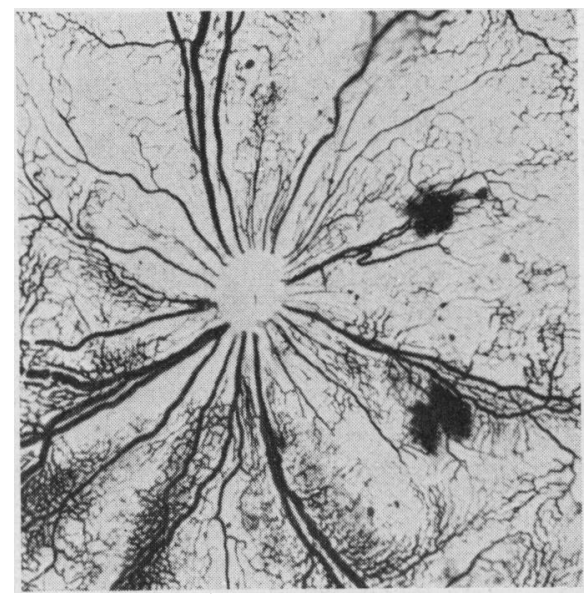

Fig. 1.-Control kitten, 1 day old (Exp. 4, k1), showing disc region of normal developing retina. Note density of vascular complexes. Injected Indian ink. Mounted flat. $\times 14$. (Whole retina shown in preliminary report).

been found that, given the same experimental conditions, very similar results may

be reproduced with remarkable regularity. The same process, although to a much less marked extent, may also be demonstrated in the developing retinal vessels in the immature eye of the young rabbit and ratling. In the rat, however, the peripheral vessels are little affected, vaso-obliteration being mainly in the postequatorial region.

Since this phenomenon was reported, its development has been studied by direct observation of the living kitten retina, using a limbal window technique, and the findings are described in a preliminary report (Ashton and Cook, 1954); here we shall describe only those features which are revealed by injection methods.

Study of retinae in which vaso-obliteration was not fully developed showed that the process commenced as a marked constriction of the arteries and arterioles; the arterioles and the arterial side of the capillary circulation were the first vessels to obliterate, and this process was followed by the disappearance of the whole capillary bed; then the main arteries and finally the main veins closed, leaving an apparertly avascular retina. Usually the blood was squeezed out of the vessels as they collapsed, but blood clot might be trapped within isolated areas. In general the process began peripherally, that is in the region where the vessels were most immature, and spread posteriorly, so that the disc region appeared to be the most resistant and was the last area to be completely obliterated.

It is of interest to note, however, that the capillary bed lying between the closely related arteries at the disc frequently disappeared early. In cases where obliteration was incomplete, the persisting arteries and veins around the disc might be united through peripheral arterio-venous anastomoses (Fig. 23).

The other vessels in the eye, such as the tunica vasculosa lentis, hyaloid artery, and choroidal circulation, showed no abnormality in the injected specimens. 
Neither did we find any evidence of vaso-obliteration in other injected organs, including the brain, of animals showing total closure of the retinal vessels. Nor have treated animals which have been allowed to survive, shown any abnormality apart from that of the retina. Our experiments thus led us to the conclusion that the vaso-obliterative effect of oxygen is confined to the retinal vessels.

Sections of eyes taken from animals subjected to 70-80 per cent. oxygen for 3-7 days, with total vaso-obliteration as seen in the fellow injected eye, showed no.patent retinal vessels, no haemorrhages, and no evidence of retinal degeneration. The ganglion cells appeared normal, and the closed vessels were represented by small clusters of endothelial cells.

The severity of the vaso-obliterative effect was found to be proportional to the degree of maturity of the retinal vascularization, to the duration of exposure to oxygen, and to the concentration of oxygen; these factors will now be discussed separately.

(2) FACTORS INFLUENCING VASO-OBLITERATIVE EFFECT

(a) Degree of Maturity of Retinal Vessels. - In analysing the experimental findings to determine the importance of the degree of maturity of the retinal vessels as a factor in the vaso-obliterative effect, the standard experimental conditions adopted were those known to be capable of producing total vaso-obliteration, i.e. $70-80$ per cent. oxygen for 3-7 days. Table $\mathrm{F}$ shows the extent of obliteration when the four age groups were subjected to this standard exposure.

TABLE I

ANALYSIS OF 21 EXPERIMENTS (45 ANIMALS) INVOLVING A SIMPLE EXPOSURE TO OXYGEN

Showing extent of vaso-obliteration in four age groups following exposure to varying concentrations of oxygen for four periods of time

\begin{tabular}{|c|c|c|c|c|c|c|}
\hline $\begin{array}{c}\text { Oxygen } \\
\text { Exposure } \\
\text { (days) }\end{array}$ & $\begin{array}{c}\text { Age } \\
\text { Group } \\
\text { (days) }\end{array}$ & $\begin{array}{c}\text { Oxygen } \\
\text { (per cent.) }\end{array}$ & $\begin{array}{c}\text { Experiment } \\
\text { Number }\end{array}$ & $\begin{array}{c}\text { Age } \\
\text { (days) }\end{array}$ & $\underset{\text { (days) }}{\text { Exposure }}$ & $\begin{array}{c}\text { Vaso- } \\
\text { obliteration }\end{array}$ \\
\hline \multirow{4}{*}{$3-7$} & \multirow{4}{*}{$\begin{array}{l}1-7 \\
\text { and } \\
8-14\end{array}$} & $70-80$ & $\begin{array}{r}1, \mathrm{k} 3 \\
4, \mathrm{k} 4 \\
2, \mathrm{k} 2 \\
1, \mathrm{k} 1 \\
1, \mathrm{k} 2 \\
20, \mathrm{k} 3 \\
7, \mathrm{k} 5 \\
27, \mathrm{k} 1 \\
27, \mathrm{k} 2 \\
31, \mathrm{k} 2\end{array}$ & $\begin{array}{r}3 \\
1 \\
2 \\
3 \\
3 \\
8 \\
8 \\
12 \\
12 \\
12\end{array}$ & $\begin{array}{l}6 \\
4 \\
3 \\
4 \\
3 \\
3 \\
5 \\
4 \\
4 \\
5\end{array}$ & $\begin{array}{l}++++ \\
+++t \\
+++ \\
++++ \\
++++ \\
++++ \\
++++ \\
+++ \\
+++ \\
++t\end{array}$ \\
\hline & & $45-55$ & $21, \mathrm{k} 1$ & 8 & 4 & $+t+$ \\
\hline & & $35-45$ & $\begin{array}{l}16, \mathrm{k} 1 \\
16, \mathrm{k} 2 \\
16, \mathrm{k} 3 \\
16, \mathrm{k} 5 \\
10, \mathrm{k} 1 \\
10, \mathrm{k} 2\end{array}$ & $\begin{array}{l}4 \\
4 \\
4 \\
4 \\
3 \\
3\end{array}$ & $\begin{array}{l}4 \\
3 \\
4 \\
4 \\
4 \\
4\end{array}$ & $\begin{array}{l}+++ \\
+++ \\
+++ \\
++t \\
++t \\
++\end{array}$ \\
\hline & & $25-35$ & $\begin{array}{l}15, \mathrm{k} 1 \\
29, \mathrm{k} 1 \\
29, \mathrm{k} 2 \\
29, \mathrm{k} 3\end{array}$ & $\begin{array}{l}1 \\
3 \\
3 \\
3\end{array}$ & $\begin{array}{l}7 \\
5 \\
7 \\
7\end{array}$ & $\begin{array}{l} \pm \\
0 \\
0 \\
\text { No result }\end{array}$ \\
\hline
\end{tabular}


TABLE I-continued

\begin{tabular}{|c|c|c|c|c|c|c|}
\hline $\begin{array}{c}\text { Oxygen } \\
\text { Exposure } \\
\text { (days) }\end{array}$ & $\begin{array}{l}\text { Age } \\
\text { Group } \\
\text { (days) }\end{array}$ & $\begin{array}{c}\text { Oxygen } \\
\text { (per cent.) }\end{array}$ & $\begin{array}{l}\text { Experiment } \\
\text { Number }\end{array}$ & $\begin{array}{c}\text { Age } \\
\text { (days) }\end{array}$ & $\begin{array}{c}\text { Exposure } \\
\text { (days) }\end{array}$ & $\begin{array}{c}\text { Vaso- } \\
\text { obliteration }\end{array}$ \\
\hline & $15-21$ & $70-80$ & $11, \mathrm{k} 1$ & 17 & 4 & + \\
\hline $3-7$ & $\begin{array}{r}22 \text { and } \\
\text { over }\end{array}$ & $70-80$ & $\begin{array}{l}13, \mathrm{k} 1 \\
14, \mathrm{c} 2 \\
8, \mathrm{k} 1 \\
23, \mathrm{c} \\
24, \mathrm{c}\end{array}$ & $\begin{array}{c}29 \\
50 \\
58 \\
\text { Adult } \\
\text { Adult } \\
\end{array}$ & $\begin{array}{l}7 \\
7 \\
5 \\
9 \\
9 \\
\end{array}$ & $\begin{array}{l} \\
0 \\
0 \\
0 \\
0 \\
\end{array}$ \\
\hline \multirow{4}{*}{$8-14$} & \multirow[t]{2}{*}{$\begin{array}{l}1-7 \\
\text { and } \\
8-14\end{array}$} & $70-80$ & $\begin{array}{l}24, \mathrm{k} 3 \\
24, \mathrm{k} 2 \\
\end{array}$ & $\begin{array}{l}4 \\
4 \\
\end{array}$ & $\begin{array}{r}9 \\
13 \\
\end{array}$ & $\begin{array}{l}+++ \\
++++\end{array}$ \\
\hline & & $25-35$ & $15, \mathrm{k} 4$ & 1 & 13 & 0 \\
\hline & $15-21$ & $70-80$ & $\begin{array}{l}25, \mathrm{k} 1 \\
25, \mathrm{k} 2 \\
36, \mathrm{k} 1 \\
36, \mathrm{k} 4\end{array}$ & $\begin{array}{l}18 \\
18 \\
18 \\
18\end{array}$ & $\begin{array}{l}10 \\
10 \\
10 \\
13\end{array}$ & $\begin{array}{l}++ \\
++ \\
+ \\
+ \text { (died) }\end{array}$ \\
\hline & $\begin{array}{l}22 \text { and } \\
\text { over }\end{array}$ & $70-80$ & $13, \mathrm{k} 2$ & 29 & 12 & 0 \\
\hline \multirow{4}{*}{$15-21$} & \multirow{2}{*}{$\begin{array}{l}1-7 \\
\text { and } \\
8-14\end{array}$} & $70-80$ & $\begin{array}{l}24, \mathrm{k} 1 \\
23, \mathrm{k} 1 \\
23, \mathrm{k} 2 \\
23, \mathrm{k} 3\end{array}$ & $\begin{array}{l}4 \\
3 \\
3 \\
3\end{array}$ & $\begin{array}{l}15 \\
20 \\
16 \\
21\end{array}$ & $\begin{array}{l}\text { No result } \\
++++ \\
++++ \\
++++\end{array}$ \\
\hline & & $25-35$ & $\begin{array}{l}35, \mathrm{k} 1 \\
35, \mathrm{k} 2 \\
35, \mathrm{k} 3\end{array}$ & $\begin{array}{l}4 \\
4 \\
4\end{array}$ & $\begin{array}{l}21 \\
20 \\
21\end{array}$ & $\begin{array}{l}0 \\
\text { No result } \\
0\end{array}$ \\
\hline & $15-21$ & $70-80$ & $36, \mathrm{k} 5$ & 18 & 20 & 0 \\
\hline & $\begin{array}{c}22 \text { and } \\
\text { over }\end{array}$ & $70-80$ & $14, \mathrm{cl}$ & 50 & 16 & 0 \\
\hline $\begin{array}{r}22 \text { and } \\
\text { over }\end{array}$ & $\begin{array}{l}1-7 \text { and } \\
8-14\end{array}$ & $70-80$ & $23, \mathrm{k} 4$ & 3 & 26 & ++++ \\
\hline
\end{tabular}

Obliteration was total or severe at 1-14 days, mild at 15-21 days, and doubtful or absent at 22 days and over; that is, during the earlier periods of vascular growth, the vessels are highly susceptible to oxygen, becoming gradually less so until the final period of retinal vascularization is reached, when only a mild obliterative effect occurs. Once the retinal circulation is fully established and the normal vascular architecture attained, that is at about 21 days old, oxygen fails to produce significant obliterative changes, and it has no structural effect whatsoever on the vessels of the adult cat.

It is thus apparent that the severity of the vaso-obliterative effect of oxygen is inversely proportional to the maturity of the retinal vessels, and this conclusion is in keeping with our previous observation that the obliterative process begins peripherally and spreads posteriorly, the main vessels of the disc region being the least susceptible.

(b) Duration of Exposure to Hyperoxia.-The influence of the period of exposure to oxygen can be deduced to a limited extent from the experiments. In Experiment 
32 , for instance, three kittens of 2 days old were subjected to 70-80 per cent. oxygen for 12,24 , and $36 \mathrm{hrs}$ respectively and were then killed immediately. Vasoobliteration was moderate in the first animal, severe in the second, and total in the third, thus showing that the vaso-obliterative effect is dependent upon the period of exposure, begins in less than $12 \mathrm{hrs}$, and is complete by $36 \mathrm{hrs}$ (Figs 3, 4, and 5).

Fig. 3.-Exp. 32, k1, after 12 hrs' exposure to $70-80$ per cent. $\mathrm{O}_{2}$. Vaso-obliteration moderate. Whole retina. $\times 4$.
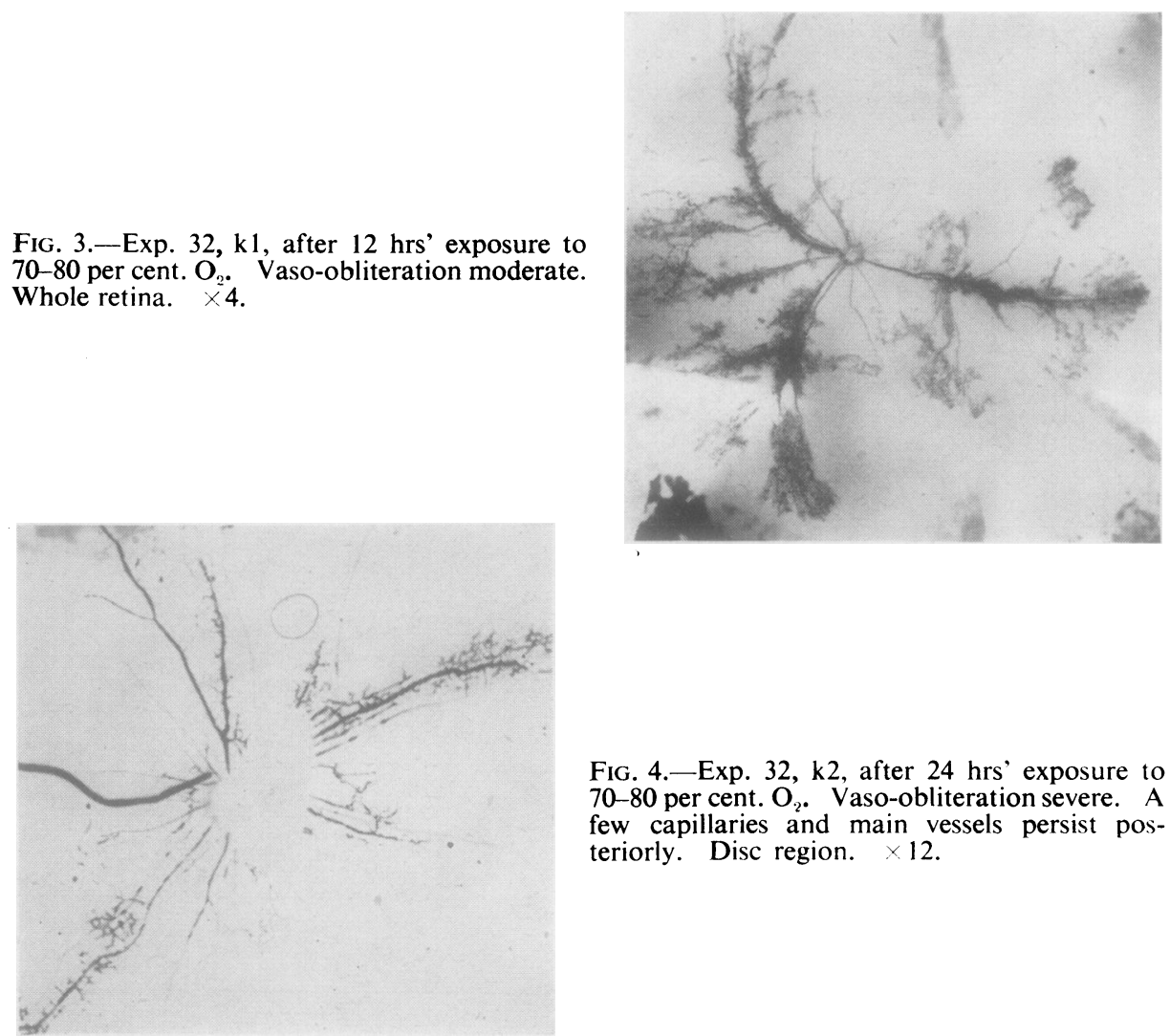

Fig. 4.-Exp. 32, k2, after 24 hrs' exposure to 70-80 per cent. $\mathrm{O}_{2}$. Vaso-obliteration severe. A few capillaries and main vessels persist posteriorly. Disc region. $\times 12$.

Fig. 5.-Exp. 32, k3, after 36 hrs' exposure to 70-80 per cent. $\mathrm{O}_{2}$. Vaso-obliteration total. Only a few attenuated vessels remain around disc. Disc region. $\times 12$.

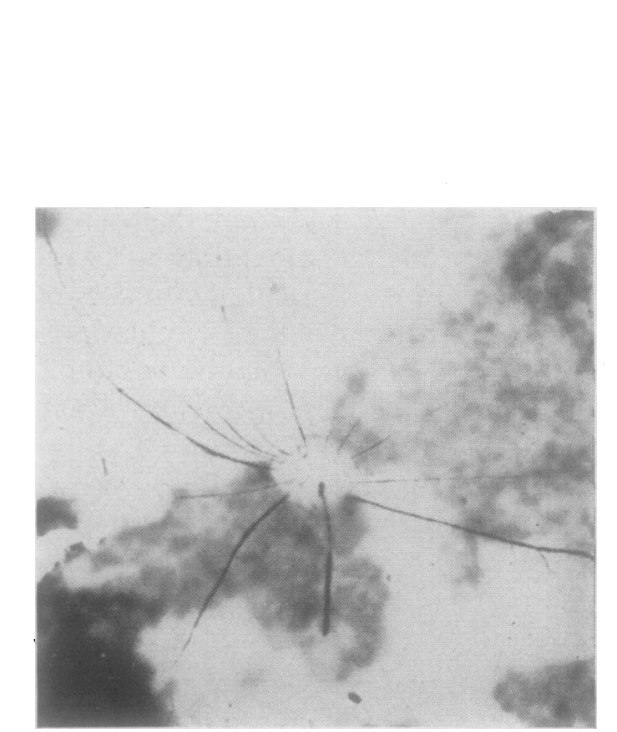


Longer periods of exposure to oxygen concentrations are analysed in Table I.

70-80 per cent. oxygen.- In the most sensitive age groups (1-14 days) the total obliteration produced in 3-7 days continued unchanged through the longer periods up to the longest time studied (26 days, Exp. $23 \mathrm{k4}$ ). In the less sensitive group (15-21 days old) vaso-obliteration was partial and peripheral; the mild effect $(+)$ obtained in Exp. 11, k1, increased to a moderate effect $(++)$ in Exp. 25, k1, k2, when the period of exposure was more than doubled; on the other hand an animal of the same age group (Exp. 36, k5) showed no vaso-obliteration after 20 days' exposure to $70-80$ per cent. oxygen, so that there is obviously some individual variation in these experiments. In the insensitive age group (22 days old and over) these concentrations of oxygen had no effect, irrespective of the period of exposure (up to 16 days).

35-55 per cent. oxygen.-Not investigated at varying periods.

25-35 per cent. oxygen.-These concentrations had no vaso-obliterative effect on the most sensitive age group (1-14 days) irrespective of the period of exposure (up to 21 days).

These long-term experiments show, therefore, that total vaso-obliteration once induced remains unaltered for at least 26 days' continuous exposure, and that retinal vessels remain unaffected by oxygen concentrations below 35 per cent. for at least 21 days' continuous exposure. The conversion of a mild to a moderate degree of vaso-obliteration in the 15-21 age group by increasing the exposure period (Exp. 11, kl and 25, kl, k2) was not confirmed in repeat experiments (36, kl, k2).

In conclusion, it is apparent that the experiments investigating short periods of oxygen exposure $(12,24$, and $36 \mathrm{hrs})$ show that the vaso-obliterative effect is directly related to the time of exposure, but this relationship is not conclusively shown in the studies of longer periods.

(c) Concentration of Oxygen.-The importance of oxygen concentrations as. a factor in the vaso-obliterative effect is shown in Table I. It has already been shown that the most sensitive age groups were those between 1-14 days old, and Table I shows that in these age groups, in a standard exposure time (3-7 days), vaso-obliteration is complete $(++++)$ with $70-80$ per cent. oxygen, severe $(+++)$ with 35-55 per cent. oxygen, and doubtful $( \pm)$ or absent $(0)$ with 25-35 per cent. oxygen.

In animals of the older age groups (15 days and over), the highest concentration of oxygen (70-80 per cent.) produces only a mild vaso-obliteration in the 15 to 21 day-old group and a doubtful effect or none in the group known to be insensitive ( 22 days old and over): it was, therefore, presumed that lower concentrations would have even less effect and no further experiments were carried out on this age group.

It is thus apparent that the severity of the vaso-obliterative effect of oxygen is directly proportional to the concentration of oxygen and that concentrations below 35 per cent. have little or no effect in the most sensitive age graups.

\section{(3) EFFECT OF TRANSFER TO AIR AFTER EXPOSURE TO HYPEROXIA}

(a) Fate of Obliterated Vessels.-When an animal which has been subjected to sufficient concentrations of oxygen to induce total retinal vaso-obliteration is transferred to air, the obliteration is found to be irreversible in the majority of the affected vessels. Such vessels as remain patent, or are able to re-open, refill with blood, but the resulting vascular architecture is grossly abnormal and consists of an attenuated, irregular cobweb of vessels without definition into arteries or veins; haemorrhages 
may appear throughout, or at the periphery of, the re-opening network (Figs 6 and 7). In the living animal it is possible that this degree of re-opening is even less than it appears to be in the post-mortem specimens, for the injection of Indian ink may to some extent force the vessel walls apart.

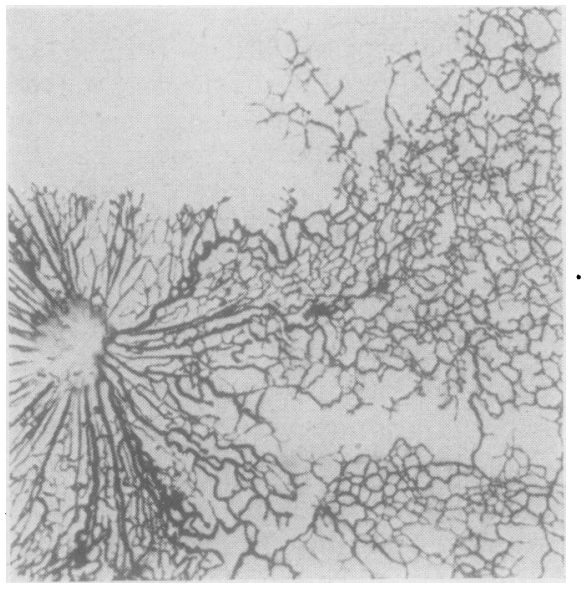

Fig. 6.-Exp. 4, k6, showing effect of 4 days' exposure to $70-80$ per cent. $\mathrm{O}_{2}$ followed by 3 days in air. The pre-existing vascular complexes have partially re-opened but the capillary network is of a grossly abnormal architecture, being cobweb in type and without definition into arteries and veins. Vascularization of retina is recommencing from disc region. $\times 14$. (Whole retina shown in preliminary report).

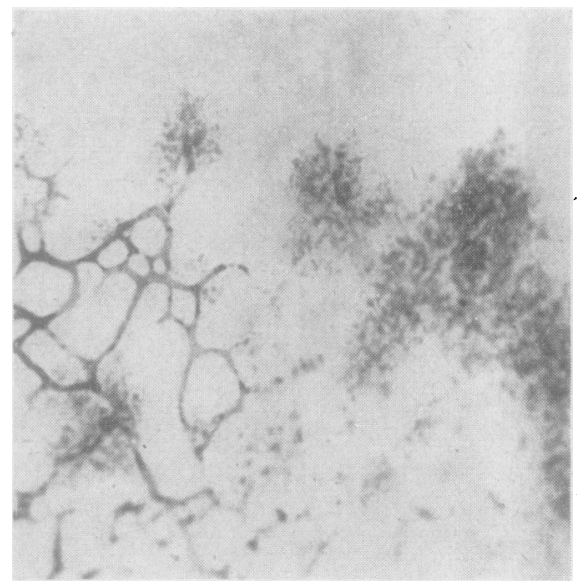

FIG. 7.-Periphery of re-opened network shown in Fig. 6. Re-opened vessels tail off into thrombosed capillaries from which many haemorrhages have occurred. $\times 50$.

We believe that the closure of the vessels is rendered permanent either by thrombosis or by the adherence of the apposing endothelial cells through plasma coagulation; the latter process is probably the more important, for no residual blood is present in the majority of collapsed vessels (this point will be further discussed in Section 4). It would, therefore, appear that the reversibility of vaso-obliteration depends upon the duration of exposure to oxygen, but in this series of experiments we have not determined the maximum period of vaso-obliteration which is completely reversible. This can only be satisfactorily assessed by direct observation of the retinal vessels in the living animal: further work on this aspect of the problem is reported in a subsequent paper (Ashton and Cook, 1954).

It is clear, however, from our injection experiments, that, where total obliteration was obtained by oxygen exposure for 3 days or more, the vascular architecture was never restored to normal on transfer to air.

In experiments where total vaso-obliteration was produced, the attenuated cobweb of vessels resulting from partial re-opening in air appeared to be inadequate to nourish the retina, and it gradually atrophied and disappeared as vascularization recommenced from the disc region, so that the final revascularized retina contained none of the original retinal vessels. In our experiments, where only partial obliteration was produced, it is difficult to decide if re-opened vessels persisted or not, but the survival of such vessels probably depends upon whether the degree of reopening permits an adequate blood flow to nourish the cells of the vessel walls, and it is likely that much of the re-opened network persists in cases where only partial vaso-obliteration occurs. 
As regards histological appearances, it has already been stated that the closed vessels are represented by clusters of endothelial cells which may give the appearance of increased cellularity in the inner layers of the retina; if, on transfer to air, the channels do not permanently re-open, the cells atrophy and disappear without trace in the finally revascularized retina. Nor does the new-vessel ingrowth show any tendency to grow along the same pathways as those of the atrophied vessels.

(b) Vaso-Proliferation.-The features of the vaso-proliferative phase in air differ according to whether the vaso-obliterative effect is complete or partial. Where the maximum effect is produced in oxygen, then, as stated above, the re-opened network is attenuated and gradually disappears; meanwhile revascularization of the retina recommences from the disc region and is well established as early as 3 days after transfer to air (Exp. 4, k6), as is shown in Fig. 6. Even at this stage it is seen that the ingrowth is abnormal in character, containing a greater number of vessels and forming a richer plexus than normal. By the 9 th day $(\operatorname{Exp} .7, \mathrm{k} 2)$ there is a profuse circular outgrowth of vessels, several layers deep, without definition into the normal three complexes, and the fine cobweb of re-opened vessels has disappeared. By the 18th day (Exp. 7, k6 and Exp. 30, k1) the vascular proliferation is even more luxuriant, and on the surface of the outgrowth there are numerbus corkscrew proliferations which extend into the vitreous as very fine arborizations or as small glomerular tufts. Numerous uncanalized and partially canalized endothelial buds may be demonstrated in the vitreous by staining with toluidine blue (Figs 8, 9, 10,11 , and 12, overleaf). At the same time there is a suggestion of new vessel formation on the anterior surface of the iris. Histologically there is evidence of intense angioblastic activity in the inner layers of the retina with extension of vaso-formative tissue and vessels into the vitreous, but there is no apparent degenerative change in the retinal neural elements and no retinal detachment (Fig. 13, overleaf). By the 30th day (Exp. 7, k3) the revascularization has progressed in a disorderly fashion in several layers within 2-3 mm. of the ora serrata in all directions; over the whole surface of the corrugated revascularized retina there is a dense network of new vessels growing into the vitreous as loops and glomerular tufts. The ingrowing vessels have now differentiated into arteries and veins. Sections confirm these findings, but now show that additional feature of multiple, acute-angled folding in the outer layers of the retina (Fig. 21), an appearance which suggests contraction of the neovascular tissue in the retina or a disproportionate development between the outer and inner layers. No true detachment is present.

The long-term results of the total vaso-obliterative effect of oxygen are demonstrated in Exp. 12. After about $2 \frac{1}{4}$ months $(\mathrm{k} 3, \mathrm{k5})$ the retina is extensively revascularized, and posteriorly the vessels have completely differentiated into arteries and veins of which there are more than normal; the profuse intravitreal proliferation is now disappearing in this area but many long convoluted vascular loops remain. The periphery of the ingrowth at the equatorial region, however, shows a wide band of dense and multi-layered vessels; many vessels extend into the vitreous as loops and glomerular tufts, and the picture is exactly like that which existed in the disc region about 7 weeks previously (Figs 14, 15, 16, and 17, overleaf).

After about $5 \frac{1}{4}$ months (k6) the retina is almost entirely revascularized, the vessels are differentiated into arteries and veins, and there are now only two main capillary networks, but the general architecture differs considerably from the normal, there being as many as twenty main vessels issuing from the disc region (Figs 18, 19 , and 20, overleaf). Many long vascular loops are seen extending into the vitreous, 


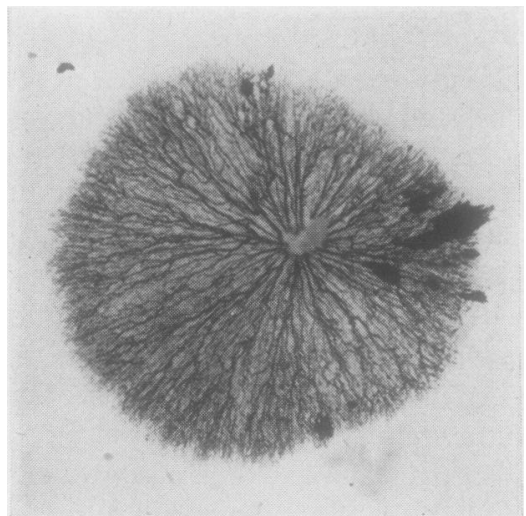

FIG. 8.-Exp. 7, k6, showing effect of 5 days' $70-80$ per cent. $\mathrm{O}_{2}$ followed by 18 days in air. The re-opened network has now disappeared and revascularization is advancing from the disc, where there is a profuse circular ingrowth of the vessels several layers in depth. The pattern of growth is completely abnormal and on the surface of the ingrowth there are corkscrew proliferations extending into the vitreous as fine arborizations or glomerular tufts. $\times 5$.

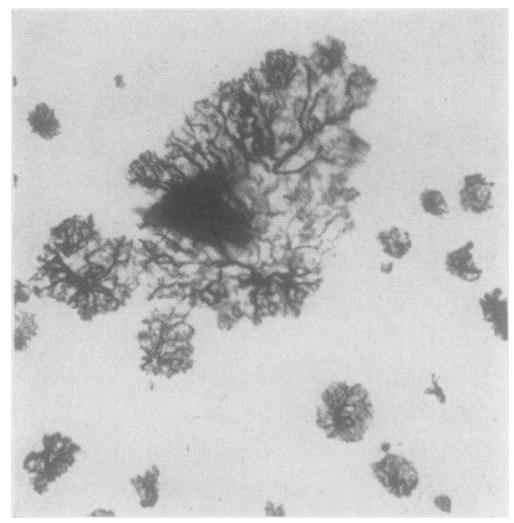

FIG. 10.-Vitreous removed from surface of vascular ingrowth shown in Fig. 8. Numerous injected glomerular tufts are present. $\times 22$.

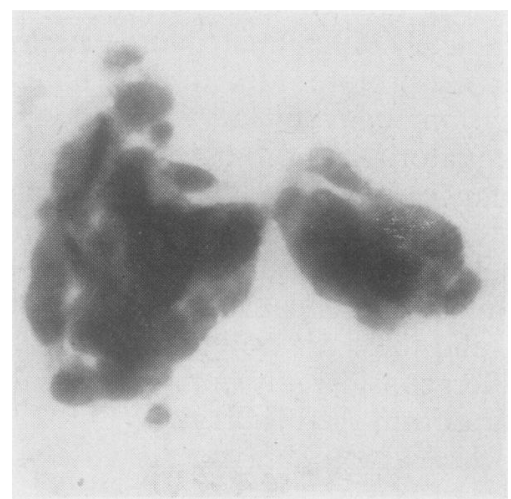

FIG. 12.-Uncanalized masses of endothelial cells from vitreous of case shown in Fig. 8. Toluidine blue. $\times 426$

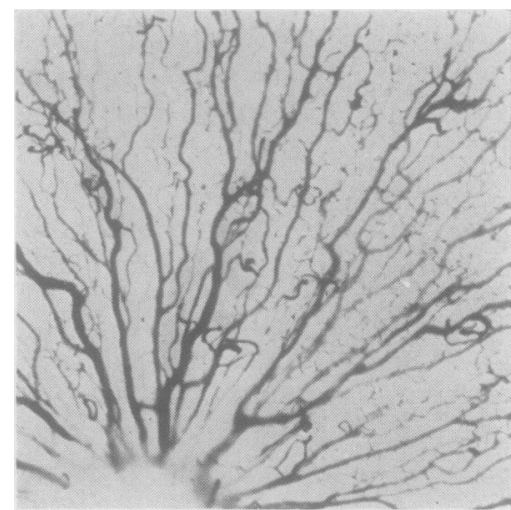

FIG. 9.-High-power view of Fig. 8, showing vascular branches extending into vitreous. $\times 22$.

Fig. 11.-High-power view of glomerular tuft shown in Fig. 10; it consists of a canalized mass of endothelial cells. $\times$ 320. (Cf. Figs 3 and 4, Ashton, 1954a).

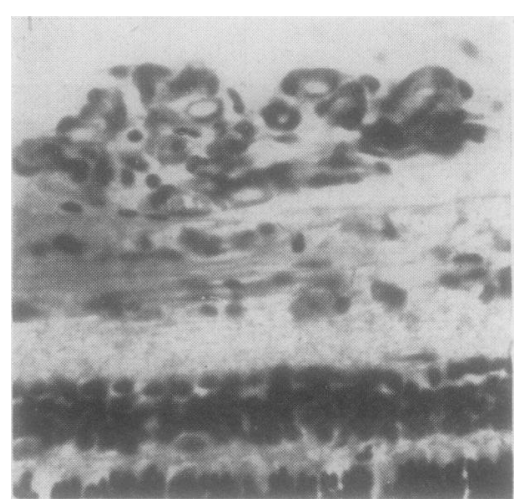

FIG. 13.- Section of retina from case shown in Fig. 8. Vaso-formative tissue extends from inner layer of retina into vitreous. Haematoxylin and eosin. $\times 340$. (Cf. Fig. 10, Ashton, 1954a) 


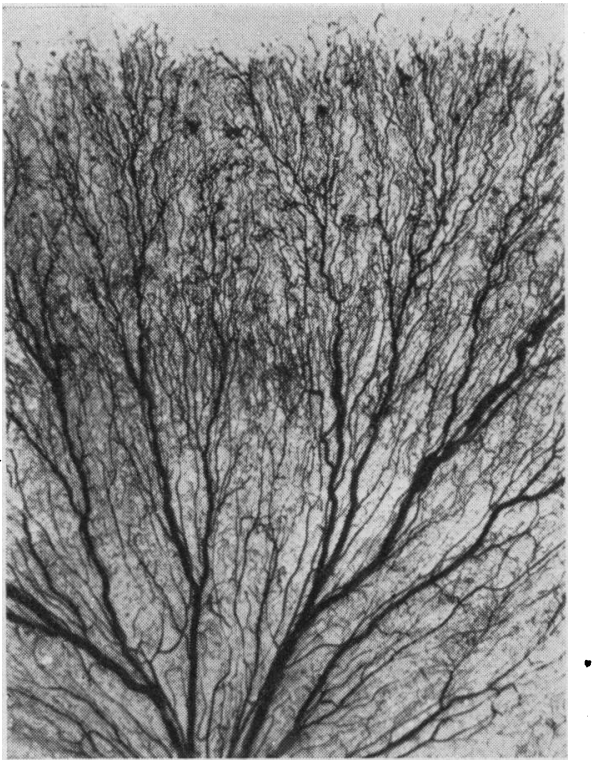

FIG. 14.-Exp. 12, k5, showing progress of retinal re-vascularization after about 2 months in air. Posteriorly (below) vessels have differentiated into arteries and veins of which there are more than normal. Intravitreal

proliferations are disappearing in this area but many loops remain (Fig. 16). At the periphery (above) there is a wide band of multi-layered vessels with numerous intravitreal loops and glomerular tufts (See Fig.15). $\times 8$.

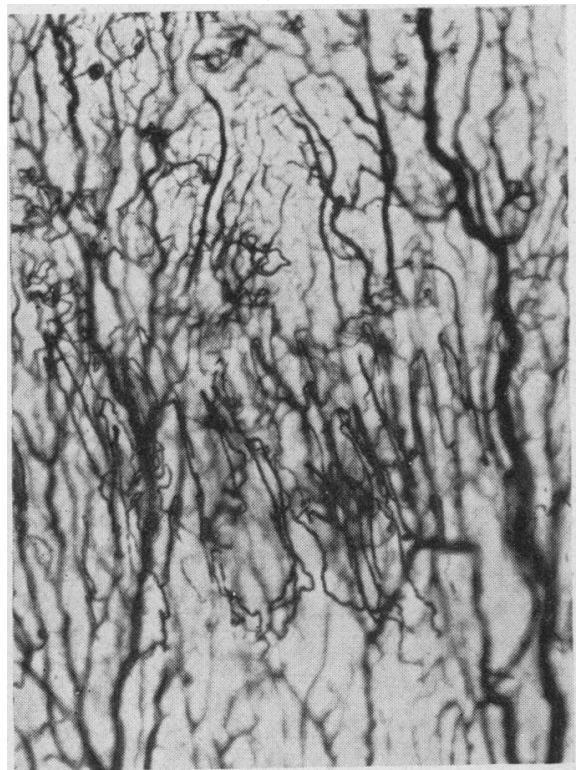

FIG. 16.-Exp. 12, k5, high-power view of posterior ingrowth showing long convoluted loops extending into vitreous. $\times 24$.

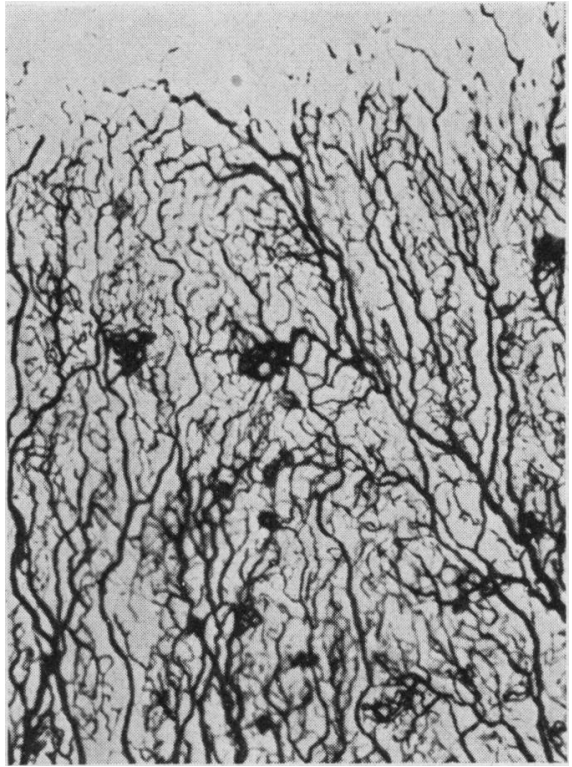

FIG. 15.-Exp. 12, k5, high-power view of periphery of ingrowth showing multi-layered vascular network and intra-vitreal glomerular tufts. $\times 24$. 


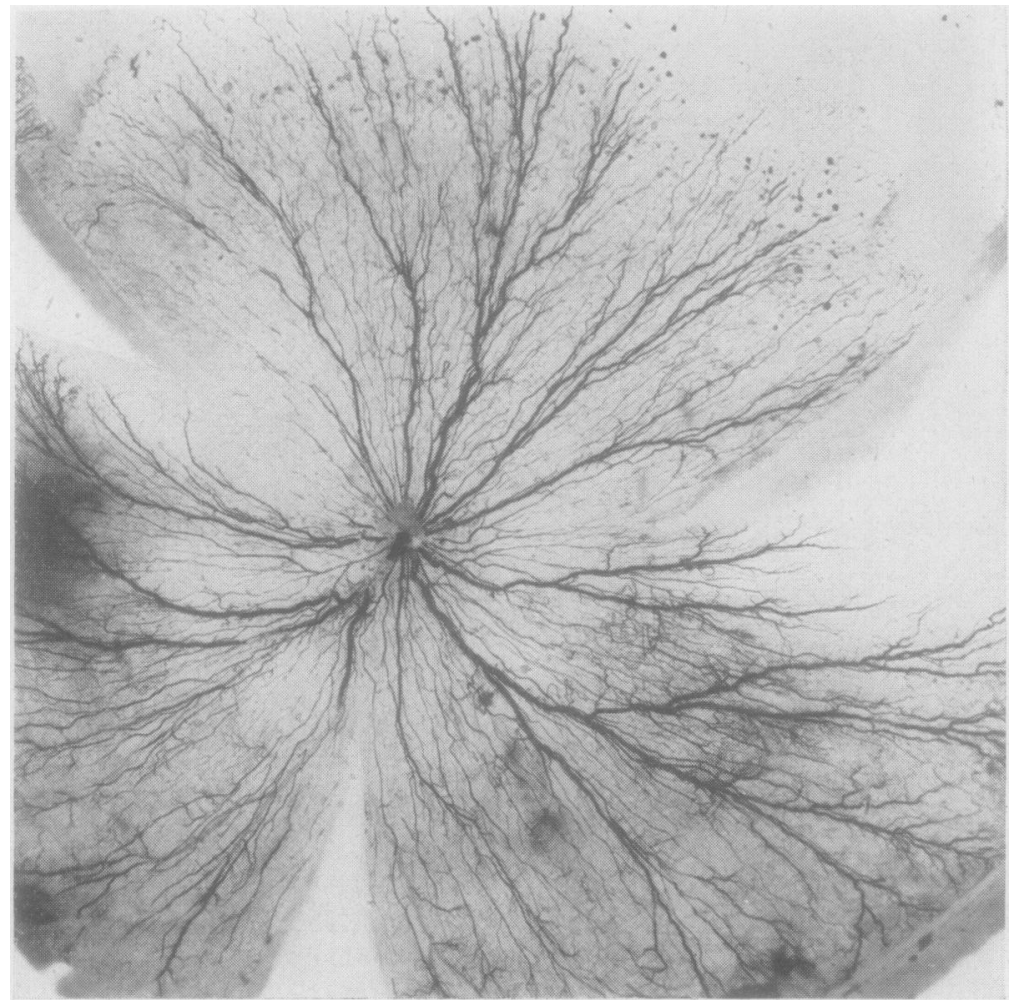

FIG. 18.--Showing progress of revascularization after about 5 months in air. The vessels have completely differentiated into arteries and veins and there are now only two main capillary networks. Many long vascular loops extend into the vitreous equatorially and numerous dot-like glomerular tufts may be seen at the periphery (above). The vascular pattern is grossly abnormal and there are many more large vessels around the disc than normal. $\times 5$.

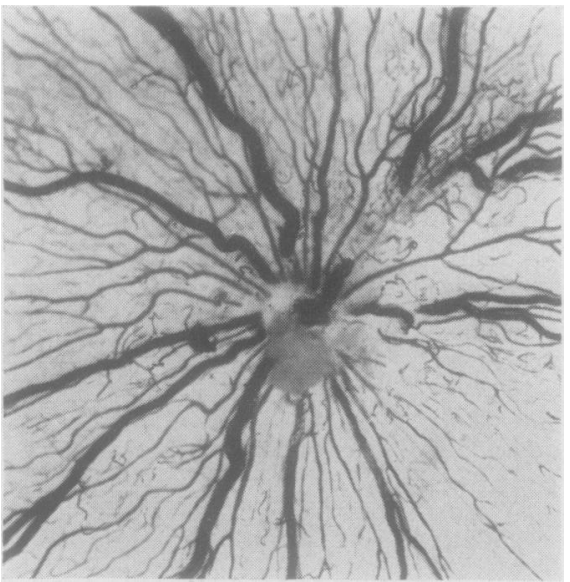

FIG. 19.-Disc region of revascularized retina. Note large number of main vessels. $\times 14$. (Compare with normal in Fig. 20).

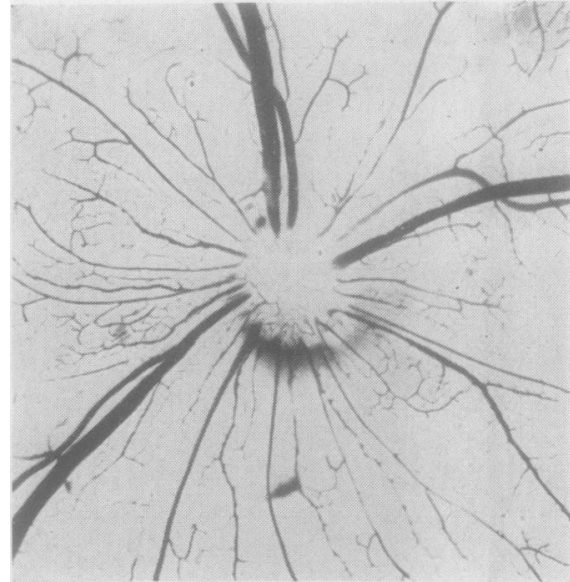

FIG. 20.-Disc region of normal adult cat.

$\times$ 14. (Compare Fig. 19). 
particularly equatorially, while at the periphery the loops are shorter and more numerous, and there are several glomerular vascular tufts. There is no histological evidence of excessive angioblastic activity in the inner layers of the retina, but vessels may be seen in the vitreous and there are small quantities of structureless eosinophilic material on the retinal surface, probably representing atrophied vascular tissue.

Apart from these abnormalities, the histological picture of the retina has been restored to normal, and the only definite evidence of its previous disruption is the presence of numerous acute-angled folds in the posterior half of the eye, some of which give a rosette appearance (Figs 21 and 22); there is no evidence of retinal detachment.

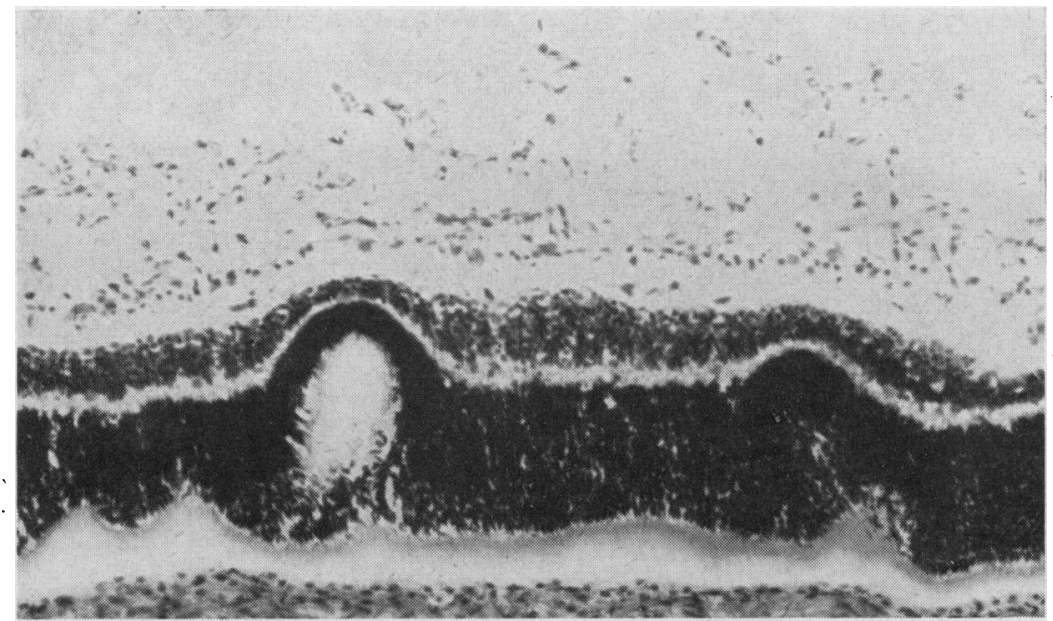

FIG. 21.-Exp. 27, k3, section of retina after 21 days in air following 4 days in $70-80$ per cent. $\mathrm{O}_{2}$. The nerve fibre layer is thickened by increased quantities of vasoformative tissue and numerous vessels extend into the vitreous. Multiple acute-angled folds are seen in the outer layers of the retina, but there is no true detachment. Haematoxylin and eosin. $\times 120$.

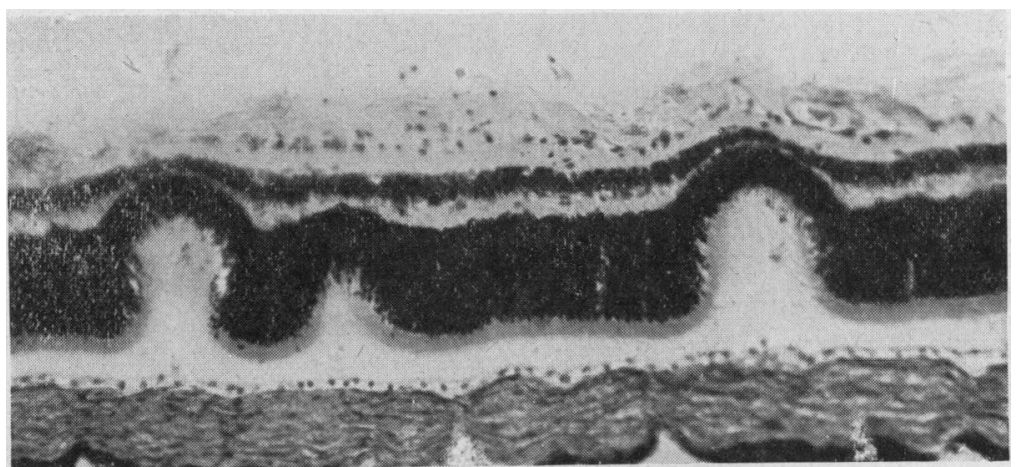

FIG. 22.-Exp. 12, k5, section of retina after 67 days in air following 4 days in $70-80$ per cent. $\mathrm{O}_{2}$. There is now no angioblastic activity in the nerve fibre layer and the intravitreal vessels have atrophied. Irregular eroded areas are present on the retinal surface and acute-angled folds persist in its outer layers. Haematoxylin and eosin. $\times 120$. 
One animal of this experiment (Exp. 12, k4), in which a maximum vasoobliterative effect was induced, is still alive and has now been observed for 10 months. The vaso-proliferative phase was studied during development and regression; retinal detachment did not occur and excellent vision appears to be retained. The retinal vascular pattern, however, is grossly abnormal, with many more large vessels around the disc than normal. In all other respects the animal is healthy.

When the vaso-obliterative effect of oxygen is partial, vascularization of the retina does not recommence from the disc region as in cases where total obliteration is produced. In Exp. 27, for instance, the vaso-obliteration was extensive but not complete since the kittens were of a less sensitive age group (12 days); three vestigial complexes persisted with peripheral arterio-venous anastomoses (Fig. 23). After 21

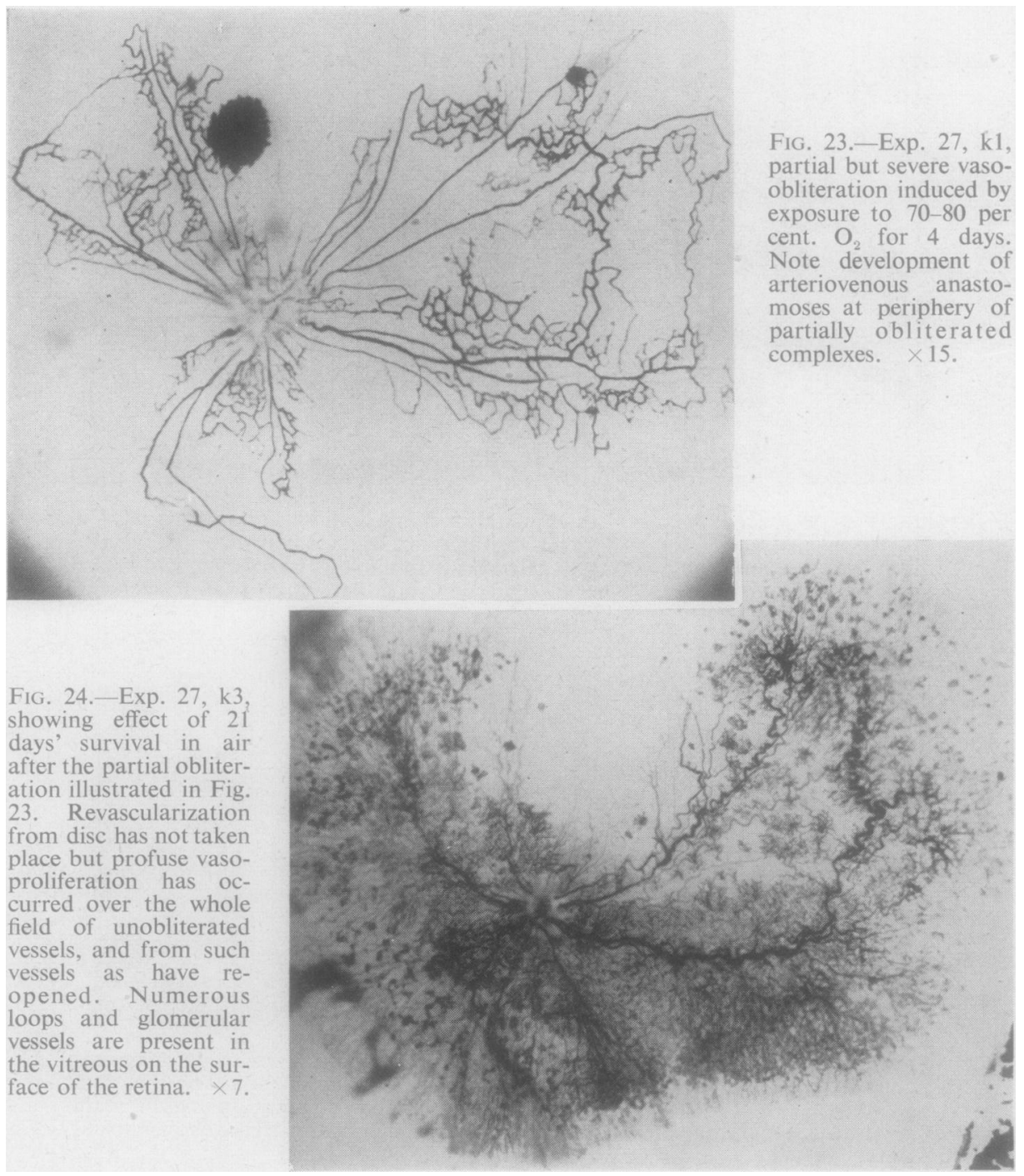


days in air ( $\mathrm{k} 3$ ), there was a massive disorderly vaso-proliferation with glomerular and looped vessels invading the vitreous, but the new-formed vessels originated from the whole field of unobliterated vessels and from such vessels as had re-opened. Although the disc region shared in this general proliferation, vascularization of the retina did not recommence from this site as in cases in which total obliteration had been induced (Fig. 24). Otherwise, however, the process was exactly similar.

Exp. 36 is particularly interesting, for it shows that when partial vaso-obliteration is restricted to the periphery or anterior portion of the retina $(\mathrm{k} 1)$, then the subsequent vaso-proliferation is similarly confined and no proliferations occur posteriorly (k2, Fig. 25). This experiment further shows the marked variability in response to oxygen exposure at this age; two other animals of the litter $(\mathrm{k} 5, \mathrm{k} 3)$ showed no vaso-obliteration or vaso-proliferation although exposed to $70-80$ per cent. oxygen for the same or longer periods.

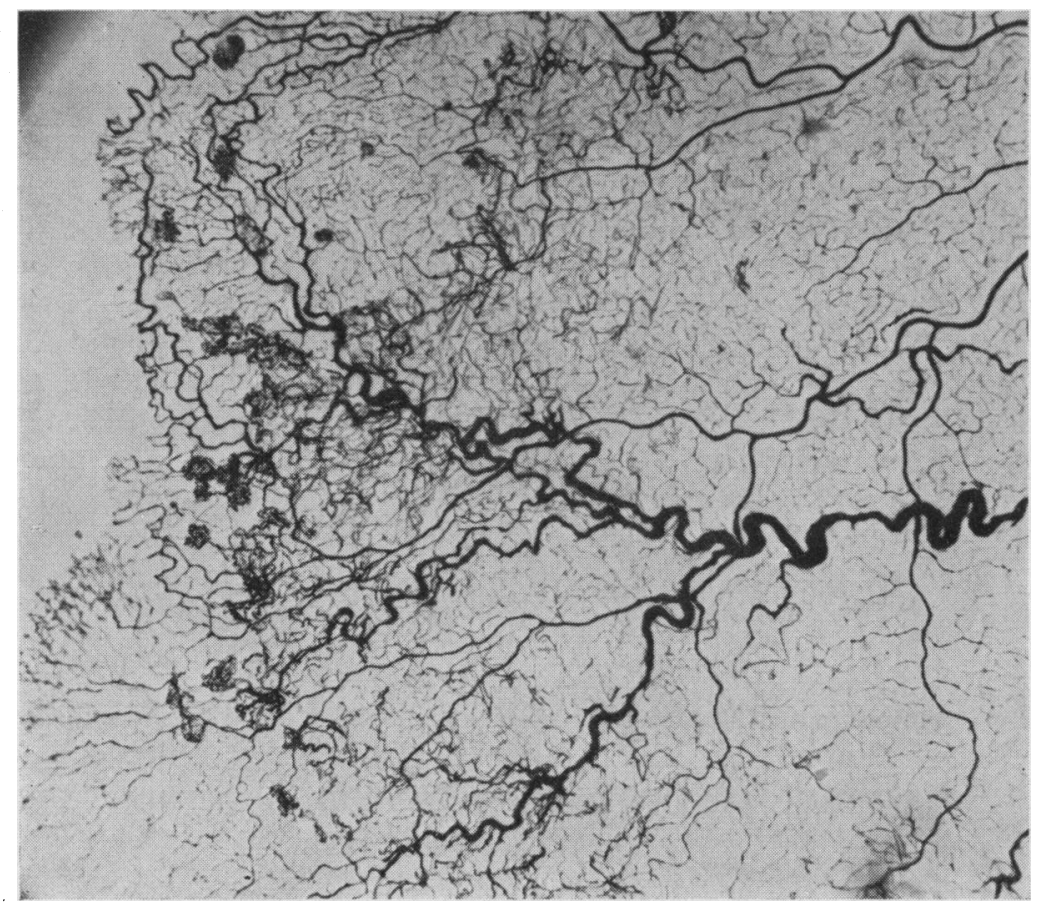

FIG. 25.-Exp. 36, k2. In this 18-day-old animal vaso-obliteration occurred only at the periphery after 10 days' exposure to $70-80$ per cent. $O_{2}$. Note that after 18 days' survival in air vaso-proliferation, consisting of tufts and loops, is similarly confined to the periphery (left). Revascularization of the retina did not take place and no vaso-proliferations occurred posteriorly. This is the type of vaso-proliferation that occurs in most cases of retrolental fibroplasia. $\times 19$.

The rate of growth of the vessels in retinal revascularization after total obliteration is much slower than normal, particularly in the terminal stages. No accurate figures are, of course, available, and in any event, there is considerable variation between animals, but in general it may be said that the normal retina is completely vascularized in about 5-6 weeks (i.e. 18 days ante-natal and 21 days post-natal), whereas the abnormal ingrowth may not be complete for 5-6 months. 
That this delay occurs in the later stages of revascularization is shown by the following comparison of approximate times:

\begin{tabular}{c|c|c|c}
\hline Vascularization & At Equator & Reaches Ora & Complete \\
\hline $\begin{array}{l}\text { Normal } \\
\text { Abnormal }\end{array}$ & $\begin{array}{c}3 \mathrm{wks} \\
5 \mathrm{wks}\end{array}$ & $\begin{array}{r}5 \mathrm{wks} \\
10 \mathrm{wks}\end{array}$ & $\begin{array}{r}6 \mathrm{wks} \\
22 \mathrm{wks}\end{array}$ \\
\hline
\end{tabular}

No rats survived after oxygen exposure, so that we were unable to study vasoproliferation in these animals. Vaso-proliferation did not occur in rabbits, because the partially obliterated vessels re-opened adequately on transfer to air.

\section{(4) FACTORS INFLUENCING OBLITERATED VESSELS}

(a) Prolonged Hyperoxia.-Experiments in which exposure to hyperoxia was continued beyond the standard period of 3-7 days showed that, providing there were no pulmonary complications, the obliterated vessels remained closed as long as the animal was in oxygen; thus in Exp. 23 the vessels remained obliterated for 16, 20, and 21 days, and in Exp. 24 for 9, 13, and 15 days.

(b) Hypoxia.- It would be of interest to know whether a transfer to hypoxia rather than to air has any influence upon the degree of re-opening of vessels or upon the subsequent vaso-proliferative phase. At the present time, however, only one experiment of this kind has been carried out (Exp. 4).

Total oxygen vaso-obliteration was induced in these animals by 4 days' $70-80$ per cent. oxygen, but one animal (k5) was transferred to hypoxia (10-15 per cent. oxygen) for 3 days, and a control (k6) to air for the same period. There was no significant difference between the degree of re-opening, neither was there a greater ingrowth of vessels in the hypoxic animal, as might have been expected. It is possible that animals kept for a longer period in hypoxia and air might show difference, but, in view of our inability to influence normal retinal vascularization to any very marked degree with prolonged hypoxia (cf. under Section 6), this would appear unlikely.

- (c) Concentration of Carbon Dioxide.-In order to eliminate the accumulation of $\mathrm{CO}_{2}$ in the oxygen incubators as a factor in the vaso-obliterative effect and to determine whether a possible vaso dilating action of a raised $\mathrm{CO}_{2}$ tension on the retinal arterioles might antagonize the obliterative action of oxygen, an experiment was carried out in which 5 per cent. $\mathrm{CO}_{2}$ was added to the 60-70 per cent. oxygen (Exp. 17). It was found that $\mathrm{CO}_{2}$ in these concentrations had no significant effect upon the phase of vaso-obliteration, and re-opening of vessels and vaso-proliferation occurred as in the control animals.

(d) Priscol (tolazoline hydrochloride).-In order to determine whether vasoobliteration might be antagonized by a vaso dilator, an animal was treated for $48 \mathrm{hrs}$ before and during oxygen exposure with Priscol (Exp. 31), which is known to have a vaso dilating action on retinal vessels in man. The test animal (k1) was given $12.5 \mathrm{mg}$. Priscol orally $6 \mathrm{hrly}$, which proved to be the maximum dose the animal could tolerate. After 5 days' exposure to 70-80 per cent. oxygen the test and control animals were killed. There was extensive vaso-obliteration in both animals, with no significant difference between the two. It may thus be concluded 
that in this single experiment Priscol did not appear to influence the vaso-obliterative effect of oxygen.

(e) Tromexan (ethyl biscoumacetate).-Since we believe that the closure of vessels by hyperoxia is rendered permanent by thrombosis or adherence of the vascular walls through plasma coagulation, it was thought that anticoagulants might permit re-opening of the vessels when the animal was transferred to air. Four experiments to investigate this point were therefore carried out (Exps 18, 20, 21 , and 22).

In these experiments Tromexan was administered as follows: Initial dose $100 \mathrm{mg} . / \mathrm{kg}$. body weight, suspended in $1 \mathrm{ml}$. methyl cellulose, per stomach tube $24 \mathrm{hrs}$ before oxygen exposure. Subsequent dosage was adjusted to maintain the prothrombin level at 3 to 4 times the normal; prothombin time was estimated by Quick's micro-technique on blood obtained from the pads. In practice it was difficult to maintain the prothrombin time constantly at the planned level.

(i) In the first experiment (Exp. 18) the animal pre-treated with Tromexan showed less avascular areas in the retina after 2 days in air following oxygen exposure than the control animal, thus suggesting that Tromexan could facilitate re-opening of the vessels, but the prothrombin times fluctuated over wide limits so that the experiment was not conclusive.

(ii) The second experiment (Exp. 20), however, was more informative and showed a very definite difference between the control and test animals, there being a total obliteration in the untreated animal $(++++)$ and only a partial obliteration $(++)$ in the kittens receiving Tromexan. Unfortunately the animals died before they could be transferred to air for sufficient time to observe fully the difference in the re-opening of the complexes.

(iii) The third experiment (Exp. 21) again showed that Tromexan affords a considerable degree of protection from the obliterative effect of hyperoxia (Figs 26 and 27, overleaf), but, contrary to expectations, the Tromexan-treated animals maintained in air for 3 days after oxygen exposure showed no marked difference from the Tromexan-treated animal killed within minutes of removal from oxygen.

(iv) The fourth experiment (Exp. 22) gave anomalous results and no conclusions were possible.

These experiments, therefore, show that Tromexan opposes, at some stage, the obliterative action of oxygen,-and that this antagonism is evident immediately the animal is returned to air. If we.assume that the drug achieves this effect by virtue of its anticoagulant properties, then, since there is no reason to suppose that an anticoagulant per se could interfere with the obliterative action of oxygen, the results would indicate that thrombosis or plasma coagulation is prevented within the closed vessels, thus permitting them to re-open on transfer to air. The fact that this effect is evident a few minutes after removal from oxygen suggests that the vascular closure itself is due to spasm, which, providing intravascular coagulation is prevented, is rapidly reversible and may be overcome by the death of the animal or possibly by the force of the Indian ink injection.

If this is the explanation of our findings in these Tromexan experiments, it is clear that all our injection preparations merely demonstrate the extent of vascular occlusion and do not show the actual degree of vascular closure due to oxygen which may have been present in life. On the other hand, Tromexan may have other unknown properties, such as a vasodilator action, which may directly oppose the action of oxygen, but the exṕeriment with Priscol would appear to elimniate this possibility. Clarification of these points must await further experiment, particularly by direct observation of the effect of oxygen on the retinal vessels in living animals both treated with Tromexan and untreated. 


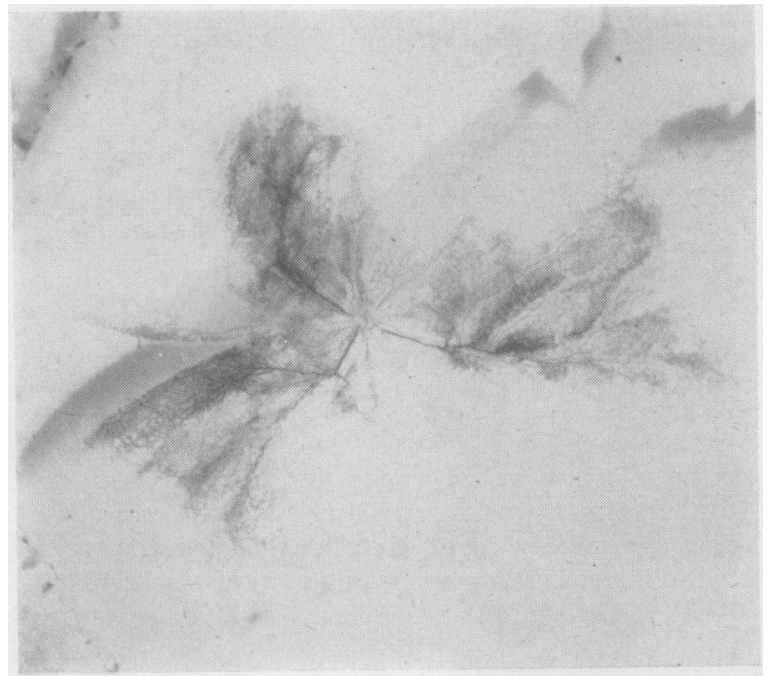

Fig. 26.-Exp. 21, k I (Tromexall experiment, control animal), showing severe degree of vasoobliteration after 4 days' exposure to $45-55$ per cent. $\mathrm{O}_{2}$. $\times 4$. (Compare Fig. 27).

Fig. 27.- Exp. 21, k5 (Tromexan experiment, test animal), showing almost normal vascular complexes. Vaso-obliteration is very slight and considerably less than in the control. $\times 4$. (Compare Fig. 26.)

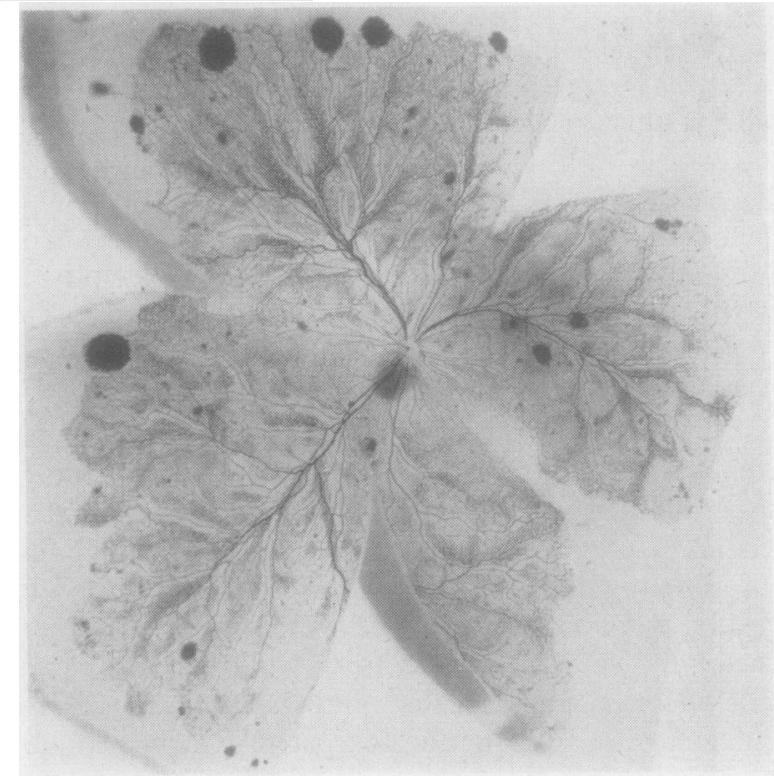

(5) FACTORS INFLUENCING VASO-PROLIFERATION

(a) Duration of Exposure to Oxygen.-With regard to the relationship of vasoproliferation to the period of exposure to oxygen, which we have already shown is an important factor in the vaso-obliterative effect, there are two important questions to consider:

(i) Is the degree of vaso-proliferation in air related to the duration of hyperoxia?

Doubtful information in answer to this question is provided by several of our experiments $(7, \mathrm{k} 3 ; 10, \mathrm{k} 6 ; 10, \mathrm{k} 5 ; 12, \mathrm{k} 2)$, but the only experiments which are strictly comparable for this purpose are Exp. 7 and Exp. 28. One kitten of the former (Exp. 7, k6) was 8 days 
FIG. 28.-Exp. 28, k1, showing effect of 18 days' survival in air after exposure to $70-80$ per cent. $\mathrm{O}_{2}$ for 10 days. The retina is revascularizing and there is profuse intravitreal extension of vascular tufts and loops. Intravitreal growth is greater than in an animal exposed to the same concentrations for 5 days. $\times 15$. Compare Fig. 8.)
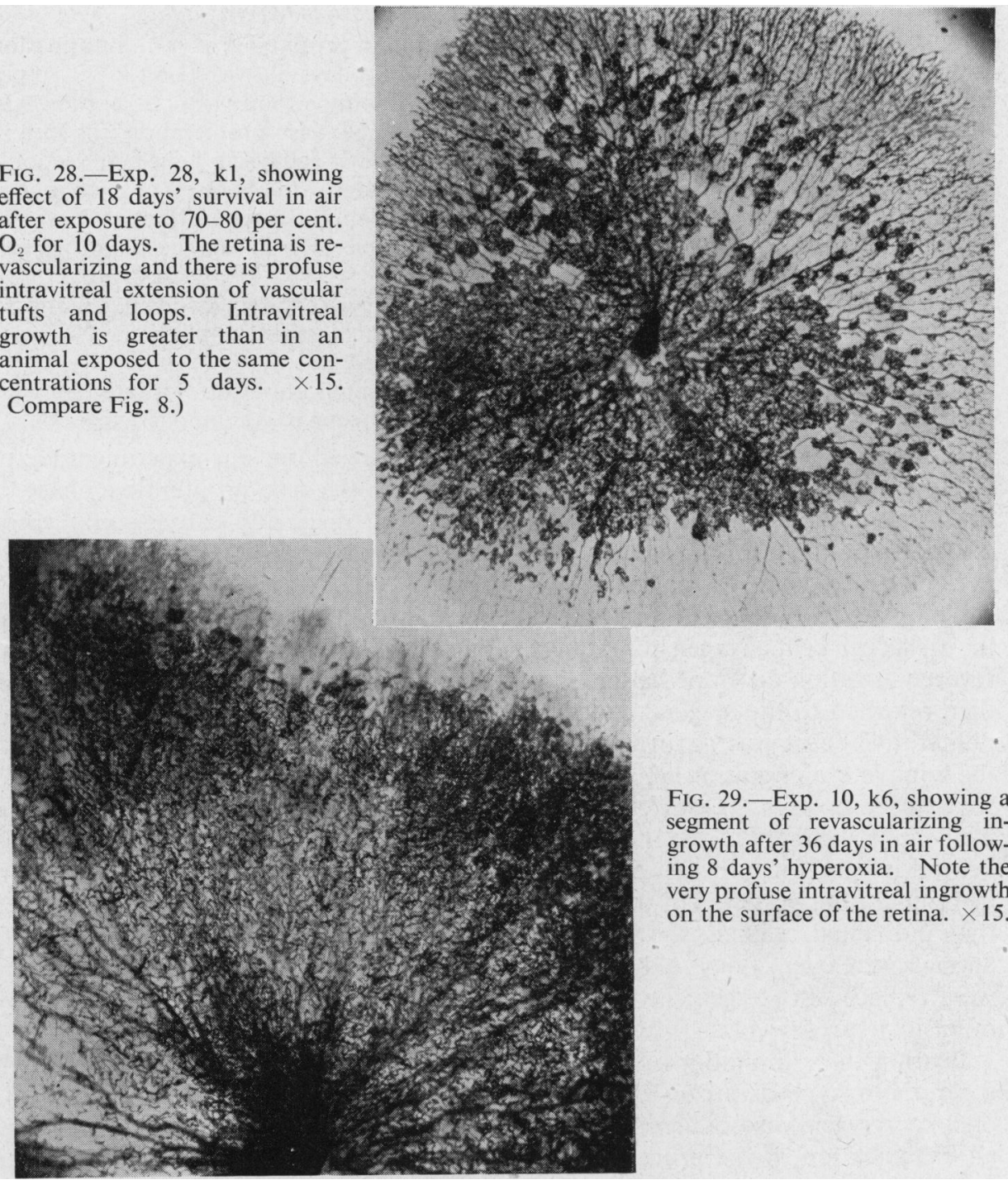

FIG. 29.-Exp. 10, k6, showing a segment of revascularizing ingrowth after 36 days in air following 8 days' hyperoxia. Note the very profuse intravitreal ingrowth on the surface of the retina. $\times 15$.

old, 5 days in 70-80 per cent. oxygen, and 18 days in air, whereas one kitten of the latter (Exp. 28, k1) was 8 days old, 10 days in 70-80 per cent. oxygen, and 18 days in air, so that the only experimental variant was the double exposure to oxygen in the case of the second animal. In both animals vaso-obliteration had been complete and the new vessel ingrowth on the 18 th day was of the same size $(6.5 \mathrm{~mm}$. diameter), but the second animal showed a much more profuse intravitreal proliferation of vessels (Fig. 28). A similar picture of profuse proliferation was seen in Exp. 10, $\mathrm{k} 6$, in an animal kept in hyperoxia for 8 days (Fig. 29). It would therefore appear that vaso-proliferation is more marked when the period of vaso-obliteration in oxygen is more prolonged, but since there is some degree of variation in response in individual animals, the evidence provided by these experiments is insufficient to be conclusive. 
(ii) Can vaso-proliferation occur if the animal is maintained in hyperoxia?

With reference to the question of vaso-proliferation in continuous oxygen, information is provided by Exps 23 and 24. In Exp. 23, kittens of 3 days old were kept in 70-80 per cent. oxygen for $16,20,21$, and 26 days. During this time total vaso-obliteration was induced and maintained until the animals were killed. No vaso-proliferation was seen in the injected retinae, and there was no excessive angioblastic activity to be seen in sections. One animal (Exp. 23, k4), however, showed a limited outgrowth of vessels at the disc, but was found at post-mortem to have pulmonary consolidation, so that, although it was in oxygen, the vaso-proliferation was probably attributable to a fall in the blood oxygen concentration.

In Exp. 24, kittens of 4 days old were kept in 70-80 per cent. oxygen for 9, 13, and 15 days; total vaso-obliteration was thereby induced and maintained until death. No vasoproliferation or excessive angioblastic activity occurred.

We therefore conclude that, providing pulmonary complications do not interfere with the absorption of oxygen, vaso-proliferation does not occur in continuous hyperoxia.

(b) Effect of Re-oxygenation.-We have so far carried out one experiment (Exp. 30) to determine the effect of returning an animal in the vaso-proliferative phase to the same conditions of hyperoxia as those which originally caused total vasoobliteration, and the subsequent effect of a second return to air after the two periods of exposure to oxygen.

Complete vaso-obliteration was produced in 4-day-old kittens by exposing them to 70-80 per cent. oxygen for 5 days. Vaso-proliferation in the form of retinal revascularization developed after transfer to air for 18 days. One animal (k2) was then returned to the original concentration of oxygen for 5 days; a definite vasoobliterative effect was again produced, but it was considerably less marked than the complete obliteration obtained by these concentrations in the case of normal vascular complexes. Transfer to air for 5 days after this second vaso-obliterative incident (k3) enhanced the intensity of vaso-proliferation, whereas an animal (k4) kept in oxygen for a further 5 days and not transferred to air showed a reduction in proliferating vessels. In interpreting these results it is important to remember that individual animals show variation in response, and that the experimental animals were over 21 days old by the time vaso-proliferation had developed and they were replaced in oxygen, i.e. they had entered the age group which is normally insensitive to oxygen.

Bearing these limitations in mind, it would nevertheless appear that, although a return to hyperoxia can to some extent control the vaso-proliferation stimulated by oxygen vaso-obliteration, the inevitable return to air is accompanied by an exacerbation of the process which is attributable to the effects of the further period in oxygen.

\section{(6) EFFECT OF HYPOXIA}

Since the experiments so far described indicate a relationship between oxygenwant and vaso-formation, one might expect that the normal developing vessels in an animal subjected to conditions of hypoxia would proliferate excessively. Three experiments carried out to investigate this possibility (Exps 3, 9, 26) show the effect of continuous hypoxia (10-15 per cent. oxygen) for exposure periods of 4 days $(3, \mathrm{k} 2), 6$ days $(9, \mathrm{k} 3), 10$ days $(9, \mathrm{k} 4 ; 10, \mathrm{k} 3)$, and 13 days $(26, \mathrm{k} 1)$. The most striking finding was intense engorgement of all the retinal vessels, which gave a much more uniform appearance than is seen in the normal pattern wherein capillary development varies greatly from one area to another. The peri-arterial capillaryfree zones were narrowed. 
In only one kitten (Exp. 9, k4) was there any evidence of increased vessel formation, and this was confined to a small area at the temporal periphery (Fig. 30) and remained within the nerve fibre layer. All sections, however, showed a definite increase in angioblastic activity, but in no case did this extend into the vitreous.

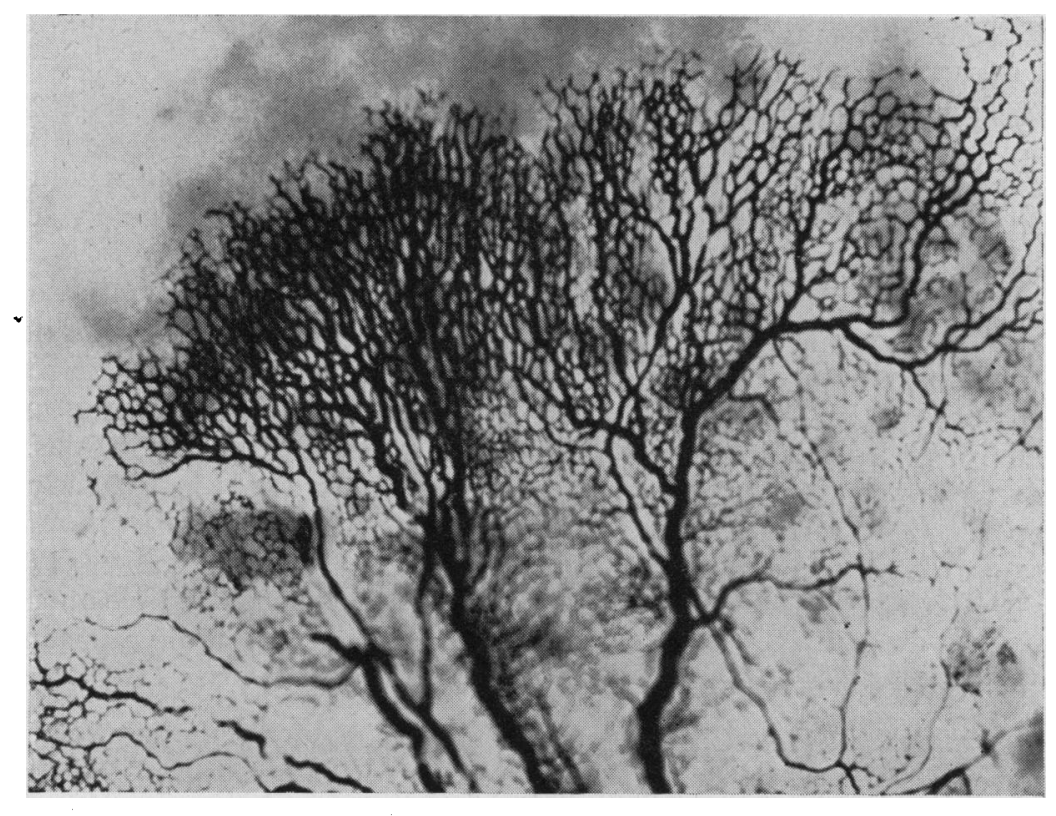

Fig. 30.-Exp. 9, k4, showing effect of exposure to $10-15$ per cent. $O_{2}$ for 10 days. In one segment of the temporal periphery vaso-formation is more active than is normally seen, but the vessels are confined to the nerve fibre layer. $\times 29$.

There was thus no evidence that ambient hypoxia can induce intravitreal vasoproliferation, and since an animal allowed to survive in air for 63 days after 13 days' hypoxia (Exp. 26, K2) showed no abnormality, we conclude that such increase in angioblastic activity as occurred was probably within the upper limits of normality.

An animal (Exp. 3, k3) exposed to hypoxia for 4 days, followed by 3 days' hyperoxia, followed by 3 days' air, showed the usual picture of partially re-opened vessels after oxygen vaso-obliteration, a process which had apparently been uninfluenced by the preliminary period of hypoxia.

\section{Discussion}

In attempting to explain the numerous experimental findings summarized above, it must be admitted that the problems are most complex, and that, since our present knowledge of retinal physiology and of the nature of vaso-formative stimuli in general is so limited, a discussion of the probable mechanisms involved can be no more than speculative. Nevertheless, the difficulties may be considerably simplified by focusing attention in turn upon the characteristics of the two main phases of vaso-obliteration and vaso-proliferation; in the case of the developing retinal vasculature these are the immediate and remote effects of oxygen exposure, but they may or may not be inter-related in the mechanism of their production. 
(1) Vaso-Obliterative Phase.-Before discussing this phenomenon in detail there are two points to be emphasized. First, although blood concentrations were not measured in our experimental animals, it is an established fact that exposure to increased concentrations of oxygen leads to an increase in the amount of oxygen in solution in the blood; the absence of abnormality among control animals in incubators and the relationship between the constrictive phenomenon, oxygen percentage, and duration of treatment, make it entirely reasonable to suppose that this pathological vascular change, which begins in the first few hours of hyperoxia, is directly or indirectly due to the oxygen-enriched atmosphere. Some reservations must be made, however, with regard to longer periods of exposure, for continuous administration, to a point where lung damage is induced, may actually result in a subnormal oxygen content of the blood (Binger and others, 1927).

Secondly, although the effects of oxygen have been extensively investigated since its isolation by Joseph Priestley in 1775, this particular effect of vaso-obliteration has not, as far as we are aware, been previously described, either in the retina or elsewhere, so that in interpreting the phenomenon we are at present somewhat confined by the limited information provided by our own investigations. It is probable, however, that the phenomenon is closely related to the existence of the capillary-free zone around the normal retinal arteries, for vaso-obliteration as seen in our experiments begins as a widening of this area; and F. W. Campbell (1951) has already demonstrated the reverse effect, namely a narrowing of the zone on lowering the oxygen tension. To simplify the discussion, the possible mechanisms involved will be discussed under separate headings.

(a) Possible Role of Vaso-Constriction.-The literature contains numerous reports that increased oxygen, either in compressed air or in hyper-oxygenated air at atmospheric pressure, causes vaso-constriction in the central nervous system in man and animals. The extensive pertinent literature has been reviewed by Bean (1945) and will not be recapitulated here, but it is of interest to note that this effect has been demonstrated in the cerebral vessels of cats (Tinel, 1927; Wolff and Lennox, 1930; Schmidt, 1934), and that it has been observed in the retinal vessels of human adults (Rosenthal, 1939; Cusick and others, 1940; Duguet and others, 1947), and of premature babies (Lamotte, 1951 ; Patz and others, 1952; Huggert, 1953).

Since hyperventilation produces a similar effect, it has been suggested (Lambertsen and others, 1953) that the effect is not due to a direct constrictor action of oxygen, but to a lowered arterial carbon dioxide tension caused by respiratory stimulation from $\mathrm{CO}_{2}$ accumulation in the cells of the respiratory centre. ${ }^{*}$ Indeed, it has been shown that, when $\mathrm{CO}_{2}$ is administered along with increased oxygen tensions, any vaso-constrictive influence which oxygen may exert on pial or retinal vessels is nullified by the dilating action of the carbon dioxide (Wolff and Lennox, 1930; Cobb and Fremont-Smith 1931; Cusick and others, 1940).

Could this particular vaso-constrictive action of oxygen alone account for vasoobliteration? We have shown that the obliteration begins as a gradual constriction of the vessels and it is known that vaso-constriction can seriously interfere with vascular growth (Ashton and Cook, 1952); on the other hand the form of vasoconstriction under discussion does not progress to vaso-obliteration, which is a phenomenon confined to the retinal vessels. Even if one were to assume that growing vessels by reason of their immature nerve supply were more susceptible

* This is the result of interference with the buffer function of haemoglobin which necessitates the transport of $\mathrm{CO}_{2}$ at a higher tension. 
than adult vessels to constrictor influences, it would be expected from the above reports that carbon dioxide would be able to prevent the action of oxygen, whereas it was found to have no effect in concentrations of up to 5 per cent.

It would, therefore, seem most unlikely that the peculiar effect of oxygen on growing retinal vessels can be related to the known vaso-constrictive action of oxygen. Information which might further elucidate this point could be obtained by studying the effect of oxygen on extra-retinal growing vessels, and experiments along these lines are described subsequently in this journal (Ashton and Cook, 1954).

(b) Toxic Effects of Oxygen.-Investigations carried out in recent years have provided evidence that increased concentrations of oxygen inhibit enzyme activity; the literature was fully reviewed by Bean (1945) and it has since been shown that cellular enzymes which depend on labile sulphur are particularly susceptible (Stadie and Haugaard, 1945a, b; Stadie and others, 1945a, b; Dickens, 1946; Haugaard, 1946). It is thus conceivable that oxygen vaso-obliteration might be related to an interference with the retinal enzyme systems. Here again, however, it is difficult to understand why other vessels, particular those of the cerebrum, are not similarly affected or why the effect should be confined to growing retinal vessels, On the basis of our present knowledge it is not possible to explain vasoobliteration solely by the action of oxygen on enzymes or by unknown toxic effects which have been postulated to account for the acute convulsive type of poisoning caused by oxygen at increased pressure. Furthermore, there is some doubt whether oxygen at atmospheric pressure is an enzyme poison; Stadie and Haugaard (1945a) studied the oxygen uptake of lung slices in dogs exposed for 48 hours to one atmosphere of oxygen and found it to be about normal.

(c) Consideration of Structure, Function, and Development.-Since the known actions of oxygen considered above have failed to provide a satisfactory explanation of retinal vaso-obliteration it is necessary to consider some new or additional mechanisms. The peculiar vulnerability of the growing retinal vessels might, for instance, be related to the unique anatomical and developmental relationships of the retinal and choroidal vessels. The retinal vessels of the kitten bud off from a ciliary ring of vessels at the disc and the process of vascularization spreads as a primitive capillary net; arteries and veins later differentiate behind the growing edge; growth occurs chiefly from the veins, as Michaelson (1948a, b) first pointed out. The choroid during this period appears well developed and obviously supplies the bulk of the retina's metabolic needs in front of the vascularized area. The effect of the hyaloid system of vessels (already atrophying and usually gone by 3 to 4 weeks) and those of the ciliary body on the oxygen-content of the vitreous is probably of minor inıportance. Here it is well to note the inter-position of a tapetal layer through the region of Bruch's membrane in the upper half of the cat's retina, for we noted no difference in effect throughout this area.

It would seem, therefore, that the choroidal circulation maintains the retinal nutrition during the early stages of development and is later supplemented by retinal vessels growing through tissue in which the oxygen tension at that time must largely be determined by the choroidal circulation. As the choroidal supply gradually becomes inadequate to meet the increasing metabolic requirements of the developing retina, of which oxygen is the most imperative, so the new vessels bud into it; it is, therefore, clear that whatever the nature of the vaso-formative stimulus, it is probably closely related to want of oxygen. 
It is reasonable to suppose that raising the oxygen tension of the choroidal blood is followed by an increased oxygenation of the retina and, therefore, of the tissue into which the retinal vessels are budding; vaso-obliteration could be explained by postulating that the vaso-formative stimulus is thus removed, further vascular growth ceases, the circulation closes down, and vascular atrophy ensues. The exceptional rapidity and extent of this effect would be in accord with the known lability of developing circulations spreading in one direction and regressing in another. In this way the two phases of vaso-obliteration and vaso-proliferation may be explained as opposite manifestations of the same mechanism-the vessels either collapsing or proliferating according to the degree of disparity between oxygen supply and demand. Consideration must, however, be given to the possibility that hyper-oxygenation of the retinal tissue produces a vaso-constricting metabolite which gradually accumulates until the retinal arterioles close in spasm to be followed by passive collapse of the venous side of the circulation. That this hypothetical factor has a specific effect on growing vessels may be related to their immature nerve supply. Herein lies the starting point for future research work which may profitably be directed towards the exclusion or demonstration and identification of such a substance.

(2) Vaso-Proliferative Phase.-Vaso-formation in the retina may be normal or abnormal and the first problem that arises is whether the stimulus in each case differs in nature or only in degree. The fundamental biological phenomenon of new vessel formation has been extensively investigated but no complete agreement has been reached on the nature of the vaso-formative stimulus; the various theories as relating to corneal vascularization have recently been reviewed by Ashton and Cook (1953), and it is clear from their study that there is much to advocate tissue hypoxia, or a metabolite produced in these circumstances, as an important factor in the vascularizing process. Such a stimulus could account for the growth of both the normal developing vessels and the abnormal proliferations, and it is most probable that the difference in response is only one of degree.

This concept of a vaso-formative factor produced in circumstances of tissue hypoxia or anoxia may readily explain our experimental findings providing it is also postulated that the factor is removed or utilized as the vessels are attracted into the tissue. Thus in normal vascularization the delicate balance between stimulus and growth ensures that there is no undue accumulation of the vaso-formative factor, so that angioblastic activity cannot become excessive; vessel growth remains confined to the inner layers of the retina in which the stimulus arises, and vascular growth ceases once the tissue is adequately supplied with oxygen. The facts that this process may be accentuated to some extent by exposing the animal to hypoxia, and retarded by hyperoxia (that is, in insufficient concentrations to cause vasoobliteration) are consistent findings.

With regard to the vaso-proliferative phase of the kitten's retina, it may be suggested that, as a result of oxygen vaso-obliteration, the retina, being in a state of active metabolism which in oxygen had been sustained by the increased nutritional range of the choroid, suffers on transfer to air an acute oxygen-lack which is much greater in degree than normal and more severe than can be induced by such hypoxic atmospheres as are consistent with survival. Since the obliterated vessels are prevented by coagulation from re-opening adequately, the vaso-formative factor accumulates in the retina, seeps into the vitreous, and may even circulate towards 
the iris through the posterior chamber. Large numbers of vessels then bud into the retina from the disc or from re-opened vessels, advance wildly into the retina, and burst into the vitreous, producing a proliferative picture far beyond the upper limits of normality. At the same time new vessels may appear on the iris. Diffusion of the vaso-formative factor outwards would not take place, as oxygen from the choroid would destroy it or oppose its action. This profuse neovascularization argues strongly in favour of a positive vaso-formative factor, for the converse theory (that vascularization occurs when an inhibitory substance is destroyed) less readily explains the cumulative effect.

This concept, considered in relation to the difference found between the marked vaso-obliterative effect of oxygen upon the normal ingrowing complexes and its relatively weak action upon the vaso-proliferative phase, wherein we assume the vaso-formative factor has amassed, implies an opposing action between the mechanism of the vaso-obliteration in hyperoxia and that of the vaso-formative factor in hypoxia. Our finding that vaso-proliferation is more marked when the duration of hyperoxia is more prolonged appears to be rather contrary to this view, suggesting an accumulation of a vaso-formative factor in hyperoxia; but this is not necessarily true, for the alternative possibility, that the longer the vessels are kept obliterated the less the degree of re-opening in air, is an equally probable explanation of the variation in vaso-proliferation.

The long-term results of the vaso-proliferative phase that, once the vessels have grown into the vitreous in response to the vaso-formative factor which had diffused into it, they gradually atrophy again, presumably because the factor is destroyed and there is no cellular activity in the vitreous to maintain the stimulus. This explains why, in complete revascularization of the retina, the intravitreal proliferations are always most in evidence peripherally, having had more time to atrophy posteriorly.

In summary, it may be said that the postulation of the elaboration of a vasoformative factor in anoxic retinal tissue is a satisfactory working hypothesis to explain the events which follow transfer to air after oxygen exposure. It is probable that this stimulus is identical with the normal in kind but excessive in degree. This should be a suitable point of departure for future research work, and the identification of the nature of this factor might well throw considerable light upon the whole problem of vascular growth.

\section{Role of Oxygen in the Aetiology of Retrolental Fibroplasia}

Before discussing the importance of oxygen therapy in the genesis of retrolental fibroplasia, it would be well to determine to what extent our experimental results parallel the pathological picture of the disease. The further studies we have carried out since the publication of our preliminary report have completely confirmed our original findings, with one important exception. It is now recognized that the retinal detachment we reported as occurring in the vaso-proliferative phase was due to artefact produced on opening the globe; histological examination has since shown that detachment does not occur in the kitten's eye, however severe the vasoproliferation induced by oxygen exposure. Thus while the experiments have exactly reproduced the histological picture of Stage I retrolental fibroplasia, the failure of the retina to detach has prevented the experimental reproduction of Stages II and III. It is not known why the kitten's retina fails to detach; it may be that there is some fundamental difference between the human and the experimental 
disease, but the lesions of the early stage are so exactly similar that an aetiological relationship seems undeniable, and we believe that the different course' is more probably referable to anatomical variations between the eye of man and that of the cat. Indeed the importance of retinal detachment as a factor in determining the course of the disease is seen also in man, for many authorities have noted a similar regression of retrolental fibroplasia in cases where no extensive detachment has occurred. As in the kitten, if detachment does not occur, the vaso-proliferation expends itself and the vessels return to an approximately normal pattern. It is not necessary to discuss here every possible facet of the relationships between the disease in man and the cat, but our studies of the pathology of the conditions have led us to the firm conclusion that, although the two disorders differ in their course, they are identical in origin. That retrolental fibroplasia is largely confined to premature babies, is commonest in the smaller weight groups, and is related to oxygen exposure, is exactly paralleled in our experimental findings.

Apart from our own work, several other experimental studies relating to oxygen and ocular abnormalities have been reported in the literature. As regards low concentrations of oxygen, lesions resembling retrolental fibroplasia have been produced in the offspring of mice subjected to an anoxic insult during pregnancy (Ingalls and others, 1952). Most workers, however, investigated the effect of high concentrations of oxygen: Coxon (1952) stated that attempts to produce retrolental fibroplasia in newborn rabbits by exposing them to oxygen concentrations of 70-80 per cent. were unsuccessful, whereas Gyllensten and Hellström (1952) succeeded in producing intra-ocular haemorrhages and hyperplastic vitreous changes in newborn mice by exposing them intermittently to 100 per cent. oxygen, but these are not the fundamental changes of retrolental fibroplasia.

Since the publication of our preliminary communication, Patz and others (1953) have reported studies in which they produced retinal vaso-proliferative changes characteristic of Stage I retrolental fibroplasia by exposing newborn mice, kittens, and puppies to 70-80 per cent. oxygen for varying periods. Since the eyes of these animals were examined only histologically, the vaso-obliterative effect of oxygen was not observed, but in a more recent investigation Patz (1954) employed the Indian ink injection technique on rats and dogs. He noted that animals exposed to oxygen concentrations of 40-50 per cent. showed a marked retinal vasoconstriction, whereas concentrations of 70-80 per cent. induced complete obliteration of the vessels after 3-5 days' exposure. These findings thus completely confirm our original report. In addition, however, Patz described the appearance of a pathological degree of angioblastic activity developing while the animals were still in continuous oxygen. As stated elsewhere, however, we would attribute this rather to a fall in blood oxygen concentration through pulmonary changes, for we have found that in animals remaining healthy in hyperoxia the contraction or obliteration of the retinal vessels is maintained; in these circumstances vasoproliferation is not to be expected, nor, in our experience, does it occur.

The clinical evidence incriminating oxygen is considerably more extensive than the experimental work, and although the reports appear conflicting they are curiously more conclusive for that reason.

The literature has been well reviewed by Zacharias (1952) and need not be repeated here, but it is of importance to stress that none of the oxygen theories of pathogenesis can now be completely accepted, because when they were advanced 
the actual effect of oxygen on growing retinal vessels was completely unknown. Now that the vaso-obliterative action of oxygen has been demonstrated in the retinal vessels of the kitten, and we have reason to suppose that the human eye may be similarly affected, many of the conflicting clinical opinions become reconcilable. Thus, the fact that there are two essential components of the disease (the one occurring in high oxygen concentrations, and the other, dependent on the extent of the first, developing in air) resolves the paradox of anoxic conditions resulting from high oxygen levels, without postulating a histotoxic anoxia, and brings together the apparently opposing views that the disease may be due either to hyperoxia or to hypoxia. Nor is it surprising that returning babies to oxygen has been found to be beneficial, for, as we have shown, the proliferating vessels are once again obliterated, although to a considerably less extent than originally.

The reported association of retrolental fibroplasia with cerebral palsy, epilepsy, and mental deficiency is not, however, explained by the vaso-obliterative effect of oxygen, which is apparently confined to the retinal vessels; this may possibly be due to a toxic effect, but one would have thought that the ordinary vaso-constrictive action of oxygen might well interfere with the high oxygen supply required for the normal development of the cells of the central nervous system.

Since it is now apparent that the vaso-proliferative phase of retrolental fibroplasia is due to retinal anoxia or hypoxia, some reference should. be made to the possibility that low blood concentrations of oxygen, whether in the foetus or premature infant, may not directly produce the disease. Provided an oxygen-laek as severe as that arising with oxygen vaso-obliteration may occur in such circumstances, there would appear to be no reason why this should not occur, for even in the adult eye vaso-proliferation is a common accompaniment of those conditions in which the retinal vessels are occluded or destroyed, such as diabetic retinopathy, central venous occlusion, or Eales's disease. Our experiments, however, suggest that low oxygen atmospheres consistent with survival are not able to induce a sufficient degree of retinal hypoxia in the normal developing eye to give rise to vaso-proliferation into the vitreous. This finding is in accord with the fact that there is no association between retrolental fibroplasia and pulmonary or cardiac disease. On the other hand it is possible that much greater degrees of anoxia may occasionally occur in utero and derange vascularization. While this possibility remains to be further investigated, it is to be remembered that neither the necessity for resuscitation (Ryan, 1952), nor the presence of cyanosis (Krause, 1946; Ryan, 1952; Unsworth, 1949), nor asphyxia (Krause, 1946) appear to have any correlation with the subsequent development of retrolental fibroplasia.

Thus the clinical, pathological, and experimental evidence justifies the recognition of the primary importance of hyperoxia in the genesis of retrolental fibroplasia, but this conclusion should not obscure the need to seek for other possible contributory factors, the existence of which is suggested by the fact that the disease is not found in all premature infants exposed to high concentrations of oxygen. On the other hand, this variation may be due simply to individual idiosyncrasy, for we have shown that in kittens of the older age group, vaso-obliteration, which is then confined to the periphery, occurs in only a proportion of the test animals.

Considering our experimental results in relation to therapy, it appears that the greatest hope lies in prophylaxis ; once the dangers of oxygen are appreciated by all responsible for the care of premature infants, so that it is administered only when 
essential and then only in the smallest quantity and for the shortest time consistent with the infant's survival, the disease should disappear or its incidence should be reduced to relatively-insignificant proportions. The recent report of Locke (1954) gives good grounds that this hope will be realized; he noted a striking fall in the incidence of the disease when the routine administration of oxygen is reduced to the minimum -it occurred in only two out of 124 babies (both mild cases) when, on the basis of previous experience, 32 cases were to be expected.

The exact amount of oxygen that may be given to a premature baby with impunity cannot, of course, be gauged by experiments on normal kittens, but the fact that concentrations below 35 per cent. have proved innocuous to these animals should be a guide. We have no experimental data on the value of graduating the withdrawal from oxygen, which has been advocated as a valuable method in preventing the disease (Szewczyk, 1951), but it is difficult to see how a gradual or rapid withdrawal could influence the course of events determined by vasoobliteration and intravascular coagulation once they have occurred. Since we have found that Tromexan allows the retinal vessel to re-open, it appears much more likely that anticoagulants offer the best preventive therapy where the risk of exposure to high oxygen concentrations must be taken.

Once the vaso-proliferative phase of the disease has begun the only apparent rational therapy is to attempt to reduce the angioblastic activity. Szewcyk (1951) recommended returning the infant to oxygen, and reported a dramatic improvement in nine cases with this treatment. While we found that re-oxygenation partially obliterated the proliferating vessels or retarded their growth, the inevitable return to air was accompanied, as was to be expected on theoretical grounds, by an exacerbation of the process, thus suggesting that such treatment of human cases may not be without its dangers.

The use of ACTH and cortisone, although originally employed on a different basis, should theoretically be of value in controlling the early stages of retrolental fibroplasia, for it is established that both hormones exert a considerable inhibitory influence on the formation of new vessels (Duke-Elder and Ashton, 1951; Ashton and Cook, 1952). Unfortunately the results have been generally discouraging, and the side-effects of these hormones appear to be particularly dangerous to the premature baby. Once a marked degree of retinal detachment has occurred the disease is irreversible and no treatment is known which can modify the subsequent developments.

In view of the tragic results of retrolental fibroplasia and the inadequacy of available treatment, the prevention of the disease is urgent and imperative; on the basis of present knowledge it appears that the problem is fortunately a simple one, being mainly a matter of ensuring that those units concerned are fully aware that oxygen, administered to premature babies, is to be regarded as a dangerous drug.

\section{Summary}

(1) High concentrations of oxygen at atmospheric pressure are able to induce in the growing retinal vessel of the kitten a type of vaso-constriction which progresses to complete obliteration of the vessels. This newlydescribed phenomenon has not been observed in extra-ocular vessels, and is apparently confined to the developing retina. It occurs also in the ratling and young rabbit, but to a much less extent. 
(2) The severity of vaso-obliteration is inversely proportional to the maturity of the vessels, and obliteration cannot be produced once the retinal vasculature is fully mature; it is directly related to the duration of exposure to oxygen, and it takes about 36 hours, as judged by injection preparations, to obtain total obliteration in the most sensitive age groups; it is directly related to the concentration of oxygen, and concentrations below 35 per cent. have little or no effect in the most sensitive age groups.

(3) On transfer to air the obliterated vessels only partially re-open, producing haemorrhages and a grossly abnormal vascular pattern. The vascular closure is rendered permanent by thrombosis or adherence of the opposing endothelial cells through plasma coagulation. Histologically the obliterated vessels are represented by clusters of endothelial cells, which, unless the vessels re-open adequately, eventually disappear.

(4) This partially re-opened network is inadequate to nourish the retina, and profuse vaso-proliferation develops. When obliteration has been total the retina is revascularized from the disc and those vessels that re-opened disappear; the new ingrowth, which is not arranged in the normal three complexes and consists of a dense circular mass of vessels, extends into the retina in a profuse and disordered manner, and glomerular tufts and vascular loops grow into the vitreous. Eventually the whole retina is revascularized, arteries and veins differentiate, and the intravitreal vessels gradually disappear in a postero-anterior direction. Retinal detachment does not occur, and, apart from acute-angled folds in the retina, the normal histology is restored and vision is retained. The fundus picture, however, is grossly abnormal, there being an irregular vascular pattern and many more main vessels around the disc than normal. Where obliteration has been partial, vasoproliferation does not originate from the disc region only, but arises from the whole field of unobliterated or re-opened vessels; in other respects the picture is similar. Where obliteration has affected only the periphery of the retinal vasculature, then vaso-proliferation and intravitreal growth is similarly confined to this region, the posterior fundus being normal-a picture which exactly parallels that seen in most cases of Stage I retrolental fibroplasia. Vaso-proliferation did not occur in rabbits exposed to hyperoxia.

(5) Several factors which might influence the above course of events were studied:

(a) In prolonged hyperoxia, it was found that obliterated vessels remain closed as long as the animal is kept in oxygen, providing no pulmonary complications ensue, and that if high concentrations of oxygen are maintained no vaso-proliferation occurs.

(b) No difference in the degree of vaso-proliferation was demonstrated on transferring animals to hypoxia rather than to air.

(c) Carbon dioxide in concentrations up to 5 per cent. was found to have no effect on either the vaso-obliterative or vaso-proliferative phases. 
(d) Priscol, in a single experiment, did not appear to modify the vaso-obliterative effect of oxygen.

(e) It was found that Tromexan profoundly modified the degree of vaso-obliteration seen after oxygen exposure; this is probably not due to an antagonism to oxygen but to the prevention of intravascular coagulation so that affected vessels are able to re-open in air.

$(f)$ In studying the effect of re-oxygenation, it was found that, although a return to hyperoxia can to some extent control the vaso-proliferation stimulated by oxygen vaso-obliteration, the inevitable return to air is accompanied by an exacerbation of the process, and that this is attributable to the further period in oxygen.

(6) Normal animals subjected to hypoxia showed a definite increase in retinal angioblastic activity, but intravitreal proliferations did not appear either in hypoxia or on transfer to air.

(7) The probable mechanisms involved in the vaso-obliterative and vasoproliferative phases are discussed, and reasons are given for supposing that vaso-obliteration cannot be explained solely in terms of the known vasoconstrictive or toxic action of oxygen. The limitation of this phenomenon to growing vessels may be attributable to the structural and functional relationships of the retinal and choroidal circulations which permit hyperoxygenation of the retina; thus the normal vaso-formative stimulus may be destroyed and the growing vessels may then collapse and atrophy; alternatively, a specific vaso-constricting metabolite with the power to obliterate immature vessels may be produced.

The features of the vaso-proliferative phase point to the production of a vaso-formative factor, elaborated in circumstances of tissue hypoxia or anoxia, which is removed or utilized as the vessels grow into the tissue. It is probable that this stimulus is identical with the normal in kind but excessive in degree. This concept explains all the events which develop in the eye on transfer to air after oxygen exposure, and may be applied to the problem of vaso-proliferation in such conditions as diabetic retinopathy, central venous occlusion, and Eales's disease.

It is pointed out that the above suggestions are no more than a working hypothesis, but future research may profitably be directed towards the identification or exclusion of such vaso-obliterative or vaso-formative factors.

(8) Relating these experimental results to retrolental fibroplasia, it is concluded that the findings exactly parallel the early stages of the human disease. The difference in the subsequent course is dependent upon the development of retinal detachment which did not occur in the kitten experiments. Despite this difference the two diseases appear identical in origin and this conclusion is supported by other experimental work and by considerable clinical evidence.

(9) Considering the results in relation to treatment it is apparent that prophylaxis is by far the most hopeful line of attack and an urgent plea is made for the control of oxygen therapy in the treatment of the premature baby. 
We are particularly indebted to the chief technician Mr. G. Knight, for his constant care in supervising the technical side of the experimental programme. We are also grateful to Messrs. A. McNeil, A. Johnston, R. Atkinson, and D. Walters for technical assistance, and to Messrs. F. Vincer, D. Brady, S. Knight, A. Krelle, P. Joshi, and J. Priest, who at some time assisted in the work. We should like to thank Dr. I. A. B. Cathie for lending us a gas chamber for our first experiments, Dr. Peter Hansell for the photographs, Miss I. M. Young for the loan of a Fry's apparatus, Mrs. P. P. Scott for assistance in providing experimental animals, Mr. N. Roberts for constructing apparatus, and Miss E. FitzGerald for secretarial help. The assistance of the Medical Research Council in providing a grant towards the expenses entailed in this work is gratefully acknowledged, and we should like to thank Sir Stewart Duke-Elder for his constant interest in this work and for his advice and criticism in the preparation of this paper.

\section{REFERENCES}

Ashton, N. (1954a). British Journal of Ophthalmology, 38, 385. (1954b). Trans. Amer. Acad. Ophthal. Otolaryng., 58, 51. and Cook, C. (1952). Brit. J. exp. Path., 33, 445.

(1953). British Journal of Ophthalmology, 37, 193. (1954). Ibid., 38, 433. WARD, B., and SERPELl, G. (1953). Ibid., 37, 513.

Bean, J. W. (1945). Physiol. Rev., 25, 1.

Bembridge, B. A., Coxon, M., Houlton, A. C. L., Jackson, C. R. S., and Smallpiece, V. (1952). Brit. med. J., 1, 675.

Binger, C. A. L., Faulkner, J. M., and Moore, R. L. (1927). J. exp. Med., 45, 849.

Campbell, F. W. (1951). Trans. ophthal. Soc. U.K., 71, 287.

Campbell, K. (1951). Med.J. Aust., 2, 48.

Cobb, S., and Fremont-Smith, F. (1931). Arch. Neurol. Psychiat. (Chicago), $26,731$.

Coxon, M. W. (1952). Proc. roy. Soc. Med., 45, 863.

Crosse, V. M., and Evans, P. J. (1952). Arch. Ophthal. (Chicago), 48, 83.

Cusick, P. L., Benson, O. O., JNR., and Boothby, W. M. (1940). Proc. Mayo Clin., $15,500$.

DiCKENS, F. (1946). Biochem. J., 40, 171.

Duguet, J., Dumont, P., and Bailliart, J. -P. (1947). J. Aviat. Med., 18, 516.

Duke-Elder, S., and Ashton, N. (1951). British Journal of Ophthalmology, 35, 695.

Fry, F. E. J. (1949). Canad. J. Res., 27, 188.

Goldman, H. von, and TOBLER, W. (1952). Schweiz. med. Wschr., 82, 381.

Gyllensten, L. J., and Hellström, B. (1952). Acta paediat. (Uppsala), 41, 577.

HaugaARD, N. (1946). J. biol. Chem., 164, 265.

Houlton, A. C. L. (1951). Trans. ophthal. Soc. U.K., 71, 583.

Huggert, A. (1953). Acta paediat. (Uppsala), $42,147$.

Ingalls, T. H. (1948). Pediatrics, 1, 315.

Ingale, Tedeschi, C. G., and HelPern, M. M. (1952). Amer. J. Ophthal., 35, 311.

JefFerson, E. (1952). Arch. Dis. Childh., 27, 329.

Krause, A. C. (1946). Arch. Ophthal. (Chicago), 36, 387.

Lambertsen, C. J., Kough, R. H., CoOper, D. Y., Emmel, G. L., Loeschcke, H. H., and Schmidt, C. F. (1953). J. appl. Physiol., 5, 471.

La Motte, W. O., JNR. (1951). "Report of Second M and R Pediatric Research Conference". Retrolental Fibroplasia, p. $26 . \quad \mathbf{M}$ and $\mathbf{R}$ Laboratories, Columbus, Ohio.

LoCKe, J. C. (1954). Arch. Ophthal. (Chicago), 51, 73.

Michaelson, I. C. (1948a). Trans. ophthal. Soc. U.K., 68, 137. (1948b). J. Anat. (Lond.), 82, 167.

Patz, A. (1954). Trans. Amer. Acad. Ophthal. Otolaryng., 58, 45.

Eastham, A., Higginbotham, D. H., and Kleh, T. (1953). Amer. J. Ophthal., 36, 1511. HOECK, L. E., and DE LA CRUz, E. (1952). Ibid., 35, 1248.

Rosenthal, C. M. (1939). Arch. Ophthal. (Chicago), 22, 385.

RuBINSTEIN, K. (1952). British Journal of Ophthalmology, 36, 303.

RYAN, H. (1952). Amer. J. Ophthal., 35, 329.

SCHMIDT, C. F. (1934). Amer. J. Physiol., 110, 137.

Silverman, W. A., Blodi, F. C., Locke, J. E., DAy, R. L., and Reese, A. B. (1952). Arch. Ophthal. (Chicago), 48, 698.

Stadie, W. C., and Haugaard, N. (1945a). J. biol. Chem., 161, 153.

L 1 (1945b). Ibid., 161, 181.

—, Riggs, B. C., and HaugaARd, N. (1945a). Ibid., 161, 175.

,$--\frac{}{(1951)}$ (194). Ibid., 161, 189.

SzEwCZYK, T. S. (1951). Amer. J. Ophthal., 34, 1649. (1952). Ibid., 35, 301.

Tinel, J. (1927). C. R. Soc. Biol. (Paris), 96, 665. 
Unsworth, A. C. (1949). Trans. Amer. ophthal. Soc., 47, 738.

WINNING, C. H. O. M. voN (1952). "Retrolental Fibroplasia and Other Forms of Pseudoglioma ". Thesis. The Hague, Netherlands.

Wolff, H. G., and Lennox, W. G. (1930). Arch. Neurol. Psychiat. (Chicago), 23, 1097.

ZACHARIAS, L. (1952). Amer. J. Ophthal., 35, 1426.

\section{APPENDIX}

\section{EXPERIMENTAL DATA}

Further details of our experimental conditions and results are shown in Tables II and III. The following abbreviations are employed:

Vaso-obliteration, degree indicated by plus signs, ++++ being total. 1 As seen in Vaso-proliferation, degree indicated by plus signs, ++++ being most profuse. $)$ injected retinae RD Revascularization from disc with intravitreal vessels.

P Peripheral intravitreal vessels

G Generalized intravitreal vessels

TABLE II

EFFECT OF HIGH CONCENTRATIONS OF OXYGEN

\begin{tabular}{|c|c|c|c|c|c|c|c|}
\hline $\begin{array}{c}\text { Oxygen } \\
\text { Concentration } \\
\text { (per cent.) }\end{array}$ & $\begin{array}{l}\text { Experiment } \\
\text { No. }\end{array}$ & $\mid \begin{array}{c}\text { Age } \\
\text { (days) }\end{array}$ & $\begin{array}{c}\text { Exposure } \\
\text { (days) }\end{array}$ & $\underset{\text { (days) }}{\text { Air }}$ & $\begin{array}{l}\text { Age at } \\
\text { Death } \\
\text { (days) }\end{array}$ & $\begin{array}{c}\text { Vaso- } \\
\text { obliteration }\end{array}$ & $\begin{array}{c}\text { Vaso- } \\
\text { proliferation }\end{array}$ \\
\hline \multirow{10}{*}{$\begin{array}{l}70-80 \text { without } \\
\text { survival in air }\end{array}$} & 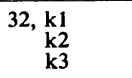 & $\begin{array}{l}2 \\
2 \\
2\end{array}$ & $\begin{array}{l}\frac{1}{2} \\
1 \\
1 \frac{1}{2}\end{array}$ & & $\begin{array}{l}2 \frac{1}{2} \\
3 \\
3 \frac{1}{2}\end{array}$ & $\begin{array}{l}++ \\
++t \\
+++t\end{array}$ & $\begin{array}{l}0 \\
0 \\
0\end{array}$ \\
\hline & $\begin{array}{r}2, \mathrm{k} 1 \\
\mathrm{k} 2 \\
\mathrm{k} 3\end{array}$ & $\begin{array}{l}2 \\
2 \\
2\end{array}$ & $\begin{array}{l}\text { Control } \\
3 \\
3 \text { (died) }\end{array}$ & & $\begin{array}{l}3 \\
5 \\
5\end{array}$ & $\begin{array}{l}0 \\
+++ \\
+++\end{array}$ & $\begin{array}{l}0 \\
0 \\
0\end{array}$ \\
\hline & $\begin{array}{r}1, \mathrm{k} 1 \\
\mathrm{k} 2 \\
\mathrm{k} 3\end{array}$ & $\begin{array}{l}3 \\
\mathbf{3} \\
\mathbf{3}\end{array}$ & $\begin{array}{l}4 \\
4 \\
6\end{array}$ & & $\begin{array}{l}7 \\
7 \\
9\end{array}$ & $\begin{array}{l}++++ \\
++++ \\
++++\end{array}$ & $\begin{array}{l}0 \\
0 \\
0\end{array}$ \\
\hline & $\begin{array}{r}23, \mathrm{k} 1 \\
\mathrm{k} 2 \\
\mathrm{k3} \\
\mathrm{k} 4\end{array}$ & $\begin{array}{l}\mathbf{3} \\
\mathbf{3} \\
\mathbf{3} \\
\mathbf{3}\end{array}$ & $\begin{array}{l}16 \\
20 \\
21 \\
26\end{array}$ & & $\begin{array}{l}19 \\
23 \\
24 \\
29\end{array}$ & $\begin{array}{l}++t+ \\
+++t \\
+++t \\
+++t\end{array}$ & $\begin{array}{l}0 \\
0 \\
0 \\
+ \text { (pneumonia) }\end{array}$ \\
\hline & 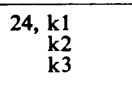 & $\begin{array}{l}4 \\
4 \\
4\end{array}$ & $\begin{array}{r}15 \\
13 \\
9\end{array}$ & & $\begin{array}{l}19 \\
17 \\
13\end{array}$ & $\begin{array}{l}\text { Sections only } \\
++++ \\
++++\end{array}$ & $\begin{array}{l}\text { Sections only } \\
0 \\
0\end{array}$ \\
\hline & $11, \mathrm{k} 1$ & $\begin{array}{l}17 \\
17\end{array}$ & $\begin{array}{c}4 \\
\text { Control }\end{array}$ & & 21 & + & $\begin{array}{l}0 \\
0\end{array}$ \\
\hline & $25, \begin{array}{l}\text { k1 } \\
\text { k2 }\end{array}$ & $\begin{array}{l}18 \\
18\end{array}$ & $\begin{array}{l}10 \\
10\end{array}$ & & 28 & $\begin{array}{l}++ \\
++\end{array}$ & $\begin{array}{l}0 \\
0\end{array}$ \\
\hline & $\begin{array}{r}13, \mathbf{k} 1 \\
\mathbf{k} 2 \\
\mathbf{k} 3\end{array}$ & $\begin{array}{l}29 \\
29 \\
29\end{array}$ & $\begin{array}{l}7 \\
12 \\
\text { Control }\end{array}$ & & $\begin{array}{l}36 \\
41 \\
32\end{array}$ & $\begin{array}{l} \pm \\
0 \\
0\end{array}$ & $\begin{array}{l}\mathbf{0} \\
\mathbf{0} \\
\mathbf{0}\end{array}$ \\
\hline & $\begin{array}{r}14, \begin{array}{l}\mathrm{k} 1 \\
\mathrm{k} 2 \\
\mathrm{k} 3\end{array} \\
\end{array}$ & $\begin{array}{l}50 \\
50 \\
50\end{array}$ & $\begin{array}{l}16 \\
7 \\
\text { Control }\end{array}$ & & $\begin{array}{l}66 \\
57 \\
57\end{array}$ & $\begin{array}{l}0 \\
0 \\
0\end{array}$ & $\begin{array}{l}0 \\
0 \\
0\end{array}$ \\
\hline & $\begin{array}{r}8, \mathrm{k} 1 \\
\mathrm{k} 2\end{array}$ & $\begin{array}{l}58 \\
58 \\
\end{array}$ & $\begin{array}{l}5 \\
\text { Control }\end{array}$ & & $\begin{array}{l}63 \\
63 \\
\end{array}$ & $\begin{array}{l}0 \\
0\end{array}$ & $\begin{array}{l}0 \\
0\end{array}$ \\
\hline
\end{tabular}


TABLE II-continued

\begin{tabular}{|c|c|c|c|c|c|c|c|}
\hline $\begin{array}{c}\text { Oxygen } \\
\text { Concentration } \\
\text { (per cent.) }\end{array}$ & $\begin{array}{c}\text { Experiment } \\
\text { No. }\end{array}$ & $\begin{array}{c}\text { Age } \\
\text { (days) }\end{array}$ & $\underset{\text { (days) }}{\text { Exposure }}$ & $\underset{\text { (days) }}{\text { Air }}$ & $\begin{array}{l}\text { Age at } \\
\text { Death } \\
\text { (days) }\end{array}$ & $\begin{array}{c}\text { Vaso- } \\
\text { obliteration }\end{array}$ & $\begin{array}{c}\text { Vaso- } \\
\text { proliferation }\end{array}$ \\
\hline \multirow{6}{*}{$\begin{array}{l}70-80 \text { with and } \\
\text { without } \\
\text { survival in air }\end{array}$} & $\begin{array}{r}7, \mathbf{k} 1 \\
\mathbf{k} 2 \\
\mathbf{k 3} \\
\mathbf{k} 4 \\
\mathbf{k 5} \\
\mathbf{k 6}\end{array}$ & $\begin{array}{l}2 \\
2 \\
2 \\
8 \\
8 \\
8\end{array}$ & $\begin{array}{l}\text { Control } \\
5 \\
5 \\
\text { Control } \\
5 \\
5\end{array}$ & $\begin{array}{r}9 \\
30 \\
18\end{array}$ & $\begin{array}{l}16 \\
16 \\
37 \\
31 \\
13 \\
31\end{array}$ & $\begin{array}{l}0 \\
0 \\
+t+t\end{array}$ & $\begin{array}{l}0 \\
++ \\
+++ \\
0 \\
0 \\
+++\end{array}$ \\
\hline & 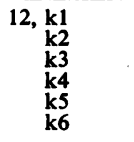 & $\begin{array}{l}3 \\
3 \\
3 \\
4 \\
4 \\
4\end{array}$ & $\begin{array}{l}4 \\
4 \\
4 \\
4 \\
4 \\
4\end{array}$ & $\begin{array}{l}65 \\
65 \\
65 \\
\text { Still alive } \\
65 \\
151\end{array}$ & $\begin{array}{l}72 \text { (died) } \\
72 \text { (died) } \\
72 \text { (died } \\
\text { Still alive } \\
73 \\
159\end{array}$ & $\begin{array}{l}\text { Sections only } \\
\text { Sections only }\end{array}$ & $\begin{array}{l}\text { Sections only } \\
+++ \text { RD } \\
\text { Sections only } \\
+++\mathbf{R D}++\mathbf{P} \\
+++\mathbf{R D}+++\mathbf{P} \\
+++\mathbf{R D}++\end{array}$ \\
\hline & $28, \mathbf{k 1}$ & 8 & 10 & 18 & 36 & & $++++\mathbf{R D}$ \\
\hline & 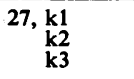 & $\begin{array}{l}12 \\
12 \\
12\end{array}$ & $\begin{array}{l}4 \\
4 \\
4\end{array}$ & 21 & $\begin{array}{l}16 \\
16 \\
37\end{array}$ & $\begin{array}{l}++t \\
+t+\end{array}$ & $\begin{array}{l}0 \\
0 \\
++++\mathbf{G}\end{array}$ \\
\hline & $\begin{array}{r}\text { 36, } \mathbf{k 1} \\
\mathbf{k} 2 \\
\mathbf{k} 3 \\
\mathbf{k} 4 \\
\mathbf{k 5}\end{array}$ & $\begin{array}{l}18 \\
18 \\
18 \\
18 \\
18\end{array}$ & $\begin{array}{l}10 \\
10 \\
10 \\
13 \\
20 .\end{array}$ & $\begin{array}{l}18 \\
31\end{array}$ & $\begin{array}{l}28 \\
46 \\
59 \\
31 \text { (died) } \\
38\end{array}$ & $\begin{array}{l}+ \text { (peripheral) } \\
+ \\
\mathbf{0}\end{array}$ & $\begin{array}{l}0 \\
+ \\
0 \\
0 \\
0\end{array}$ \\
\hline & $19, \mathrm{kl}$ & 22 & 5 & 23 & 50 & & 0 \\
\hline
\end{tabular}

TABLE III

EFFECT OF OTHER CONCENTRATIONS OF OXYGEN

\begin{tabular}{|c|c|c|c|c|c|c|c|}
\hline $\begin{array}{c}\text { Oxygen } \\
\text { Concentration } \\
\text { (per cent.) }\end{array}$ & $\begin{array}{l}\text { Experiment } \\
\text { No. }\end{array}$ & $\left|\begin{array}{c}\text { Age } \\
\text { (days) }\end{array}\right|$ & $\underset{\text { (days) }}{\text { Exposure }}$ & $\underset{\text { (days) }}{\text { Air }}$ & $\begin{array}{l}\text { Age at } \\
\text { Death } \\
\text { (days) }\end{array}$ & $\begin{array}{c}\text { Vaso- } \\
\text { obliteration }\end{array}$ & Vaso-proliferation \\
\hline $\begin{array}{l}35-45 \text { without } \\
\text { survival in air }\end{array}$ & 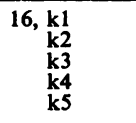 & $\begin{array}{l}4 \\
4 \\
4 \\
4 \\
4\end{array}$ & $\begin{array}{l}4 \\
3 \\
4 \\
3 \text { (died) } \\
4\end{array}$ & $\begin{array}{l}1 \text { (died) } \\
1 \text { (died) } \\
1 \text { (died) }\end{array}$ & $\begin{array}{l}9 \\
7 \\
9 \\
7 \\
9\end{array}$ & $\begin{array}{l}+++ \\
+++ \\
+++ \\
\text { Sections only } \\
+++\end{array}$ & $\begin{array}{l}\mathbf{0} \\
0 \\
0 \\
\text { Sections only } \\
0\end{array}$ \\
\hline \multirow{3}{*}{$\begin{array}{l}25-35 \text { with and } \\
\text { without } \\
\text { survival in air }\end{array}$} & $\begin{array}{r}29, \begin{array}{r}\mathbf{k} 1 \\
\mathbf{k} 2 \\
\mathbf{k 3}\end{array} \\
\end{array}$ & $\begin{array}{l}\mathbf{3} \\
\mathbf{3} \\
\mathbf{3}\end{array}$ & $\begin{array}{l}5 \\
7 \\
7\end{array}$ & • & $\begin{array}{r}8 \\
10 \\
10\end{array}$ & $\begin{array}{l}0 \\
0 \\
\text { Sections only }\end{array}$ & $\begin{array}{l}\mathbf{0} \\
0 \\
\text { Sections only }\end{array}$ \\
\hline & 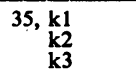 & $\begin{array}{l}4 \\
4 \\
4\end{array}$ & $\begin{array}{l}21 \\
20 \\
21\end{array}$ & & $\begin{array}{l}25 \\
24 \\
25\end{array}$ & $\begin{array}{l}\mathbf{0} \\
\text { Sections only } \\
\mathbf{0}\end{array}$ & $\begin{array}{l}\mathbf{0} \\
\text { Sections only } \\
\mathbf{0}\end{array}$ \\
\hline & $\begin{array}{r}15, \mathbf{k} 1 \\
\mathbf{k} 2 \\
\mathbf{k} 3 \\
\mathrm{k} 4\end{array}$ & $\begin{array}{l}1 \\
1 \\
1 \\
1\end{array}$ & $\begin{array}{r}7 \\
14 \\
14 \\
14\end{array}$ & $\begin{array}{l}33 \\
75\end{array}$ & $\begin{array}{r}8 \\
48 \\
90 \\
15\end{array}$ & $\begin{array}{l} \pm \\
0\end{array}$ & $\begin{array}{l}\mathbf{0} \\
\mathbf{0} \\
\mathbf{0} \\
\mathbf{0}\end{array}$ \\
\hline \multirow{2}{*}{$\begin{array}{l}\text { 10-15 with and } \\
\text { without } \\
\text { survival in air }\end{array}$} & $\begin{array}{r}9, \mathbf{k 1} \\
\mathbf{k 2} \\
\mathbf{k 3} \\
\mathrm{k4} \\
\mathrm{k5} \\
\end{array}$ & $\begin{array}{l}4 \\
4 \\
5 \\
4 \\
4 \\
\end{array}$ & \begin{tabular}{|l|} 
Control \\
Control \\
6 \\
10 \\
1 (died)
\end{tabular} & & $\begin{array}{r}4 \\
14 \\
11 \\
14 \\
5\end{array}$ & $\begin{array}{l}\mathbf{0} \\
\mathbf{C} \\
0 \\
0\end{array}$ & $\begin{array}{l}\mathbf{0} \\
0 \\
0 \\
+\end{array}$ \\
\hline & $\begin{array}{r}26, \begin{array}{r}\text { k1 } \\
\mathbf{k} 2 \\
\mathbf{k} 3\end{array} \\
\end{array}$ & $\begin{array}{l}4 \\
4 \\
4\end{array}$ & $\begin{array}{l}13 \\
13 \\
10\end{array}$ & 63 & $\begin{array}{l}17 \\
80 \\
14\end{array}$ & $\begin{array}{l}0 \\
0\end{array}$ & $\begin{array}{l}0 \\
0 \\
0\end{array}$ \\
\hline
\end{tabular}


TABLE IV

EFFECT OF EXPOSURE TO OXYGEN COMBINED WITH OTHER TREATMENT

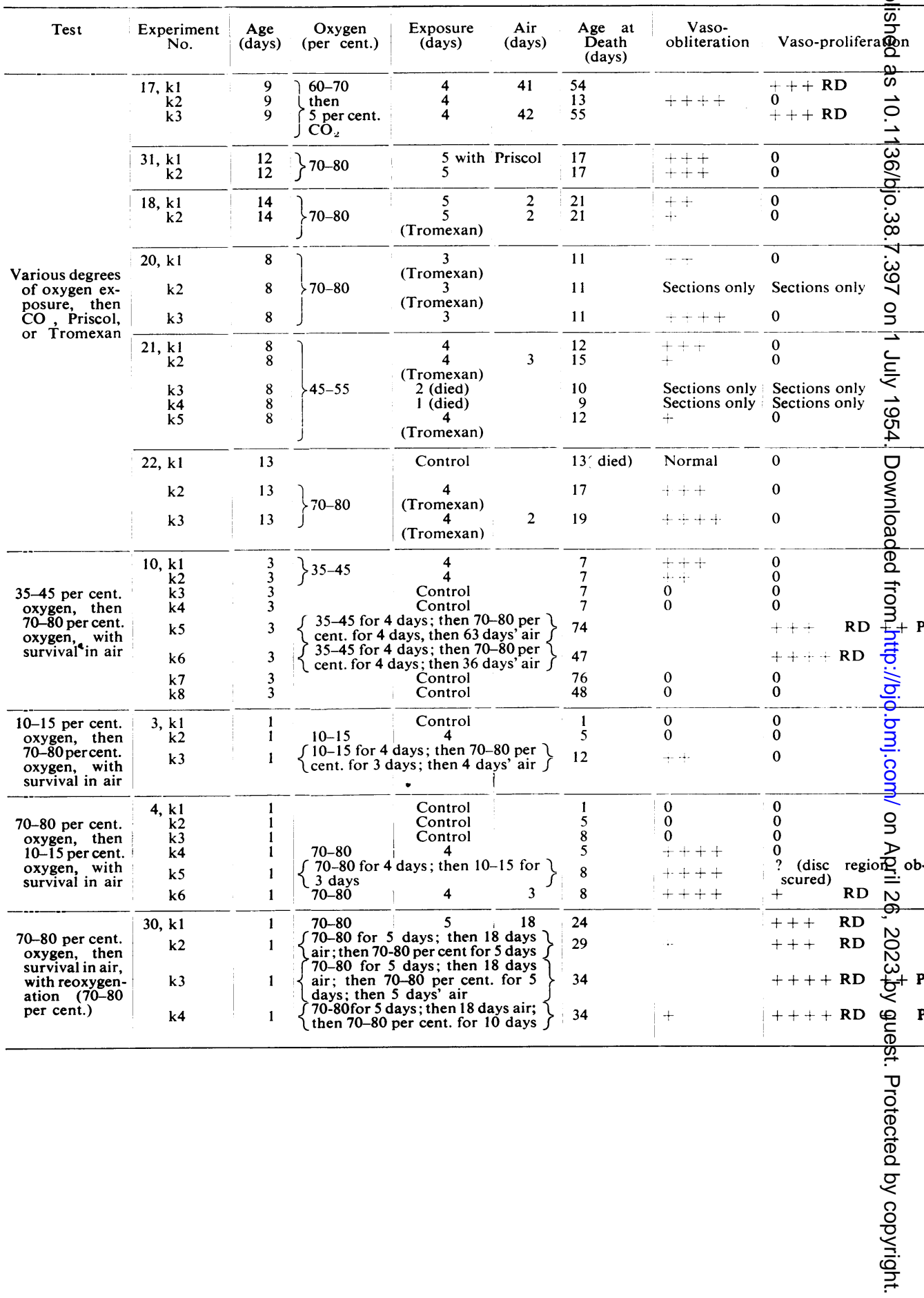

